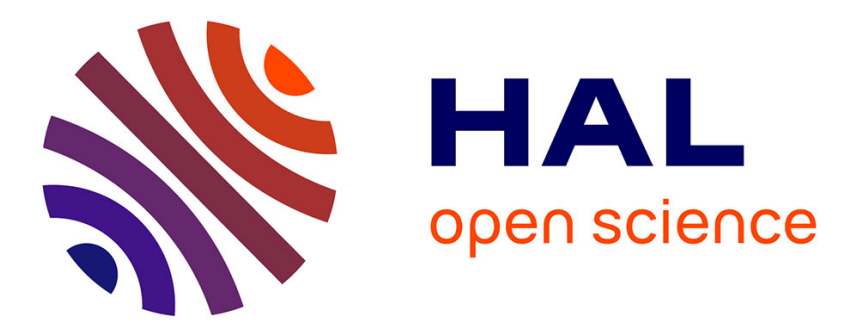

\title{
EXPERIMENTAL SITUATION IN DEEP INELASTIC REACTIONS WITH RESPECT TO THE RAPIDLY RELAXED MODES.
}

Jöel Galin

\section{- To cite this version: \\ Jöel Galin. EXPERIMENTAL SITUATION IN DEEP INELASTIC REACTIONS WITH RESPECT TO THE RAPIDLY RELAXED MODES.. European Conference On Nuclear Physics With Heavy Ions, 1976, Caen, France. pp.C5-83-C5-107, 10.1051/jphyscol:1976506 . jpa-00216586}

\section{HAL Id: jpa-00216586 https://hal.science/jpa-00216586}

Submitted on 1 Jan 1976

HAL is a multi-disciplinary open access archive for the deposit and dissemination of scientific research documents, whether they are published or not. The documents may come from teaching and research institutions in France or abroad, or from public or private research centers.
L'archive ouverte pluridisciplinaire HAL, est destinée au dépôt et à la diffusion de documents scientifiques de niveau recherche, publiés ou non, émanant des établissements d'enseignement et de recherche français ou étrangers, des laboratoires publics ou privés. 
EXPERIMENTAL SITUATION IN DEEP INELASTIC REACTIONS WITH RESPECT TO THE RAPIDLY RELAXED MODES.

\title{
JoëI Galin
}

Institut de Physique Nucléaire B.P. n 1,91406 Orsay, France

\begin{abstract}
Résumë : Après avoir rapidement passé en revue les différentes techniques les plus frêquemment utilisées dans 1 'étude du processus très inélastique, la question relative au nombre de corps dans la voie de sortie est examinêe. Il y a maintenant de très fortes preuves expérimentales indiquant que seuls deux principaux ensembles nucléaires naissent de l'interaction quelle que soit la taille des nucléides dans la voie d'entrée. Ensuite, parmi les trois degrés de liberté collectifs les plus significatifs mis en jeu dans les réactions très inélastiques (assymétrie de masse, mouvement relatif, et rapport du nombre de protons à celui de neutrons) nous avons considéré les deux derniers qui semblent être relaxés de façon rapide. L'évolution en temps est étudiée en considérant systématiquement la distribution des produits individuels de réaction en fonction, à la fois, de leur énergie cinétique et de leur distribution angulaire. Une tentative de classement des systèmes étudiés, basêe sur 1'allure des distributions angulaires, est donnée en fonction d'un paramètre semblable au paramètre de Sommerfeld. L'action des forces de viscosité qui sont responsables de l'amortissement du mouvement relatif est étudiée par le biais des degrés de liberté internes des produits de réaction (énergie d'excitation et de déformation, spin). Enfin, il est montré que la relaxation du degré de liberté lié à l'excès de neutrons est très rapidement atteinte (même plus rapidement que ne l'est la relaxation du degré de liberté associé au mouvement relatif).
\end{abstract}

Abstract : After having briefly surveyed the different techniques the most commonly used in deep inelastic studies the problem of the body number in the exit channel is discussed. There are now strong experimental evidences that only two major nuclear pieces are left at the scission stage whatever is the size of the nucleides in the entrance channel. Then, among the most three relevant collective degrees of freedom involved in deep inelastic collisions (mass asymmetry, relative motion, neutron to proton ratio) the last two ones which appear to be rather rapidly relaxed are considered. The time evolution is looked at by surveying the individual nucleus yield distributions as a function of their kinetic energy and angular distribution. A tentative classification of the interacting systems based on the angular distribution pattern of the products is given as a function of a Somerfeld-like parameter. The action of the viscous forces which are responsible of the kinetic energy damping is investigated through the analysis of the internal degrees of freedom of the reaction products (excitation energy, deformation energy and spin). Finally the relaxation of the neutron excess degree of freedom is shown to be very rapidly achieved (even more rapidly than is the relaxation of the degree of freedom associated to the relative motion).

\section{INTRODUCTION}

During the last three or four years deep inelastic reaction studies have known an explosive growth. The availability of heavy-ion accelerators delivering heavier and heavier beams with good intensities is largely responsible for the success of the field. Nevertheless the massive projectiles such as $\mathrm{Kr}$ and $\mathrm{Xe}$ are not necessarily involved in these studies and more and more work has been conducted on tandems with "light" heavy ions in order to study the macroscopic aspects of nuclear collision phenomena.

Deep inelastic collisions between heavy ions were first observed 15 years ago in the pion- 
ner work of Kaufmann and Wolfgang $|1|$. However, for a long time these reactions did not raise much interest. They were seen as a by-product in most of the spectroscopic studies but scarcely considered. And, apart some isolated experiments carried out around 1970, mainly at Dubna [2] and Orsay [3-4], one has to wait until 1973-1974 to see a fantastic burst in the development of both experimental and theoretical approaches. This sudden interest was somewhat triggered by the failure in synthetizing super-heavy species. Quite soon, it was realized that super-heavies could not be produced as compound nuclei because of the impossibility of fusing completely together two massive nuclei. Instead, different reaction channels were opened which brought a lot of interest.

As it was already pointed out by Lefort [5], when two heavy ions interact the possible reaction mechanisms cannot be simply divided into fast direct processes and slow compound nucleus processes. It appears that other interactions do occur involving the whole reaction time range from direct interaction to compound nucleus characteristic times. Furthermore for some degrees of freedom the number of nucleons which are involved is larger than the few nucleons involved in direct reactions but does not reach the totality of them as in compound nucleus processes.

There have been some semantic difficulties to qualify these new reaction mechanisms. According to the different groups they are called "quasi-fission" or "fission-like" (for those who have in mind the fission process), "strongly damped" or "relaxed" phenomena, "hard grazing" or " "deep inelastic" collisions. The later expression being so far the most commonly used we shall adopt it all along this talk.

A deep inelastic collision between two nuclei could be roughly depicted as follows. During such a collision, a large amount of the kinetic energy in the relative motion is dissipated into the internal degrees of freedom as well as some amount of the orbital angular momentum is converted into intrinsic angular momentum of the products. In the course of such a process there are some rearrangements in both the relative size (mass) of the partners $\left(A_{i}\right)$ and in their neutron excess $\left.\left(A_{i}-z_{i}\right) / z_{i}\right)$. However the interaction time is not sufficient to allow a complete statistical equilibration in all the degrees of freedom. The disrup- tion of the transitory complex system occurs before a compound nucleus regime is established.

As suggested by Swiatecki and Bjornholm [6] the deep inelastic process resembles the fission process in many respects. The first stage of the interaction process, when the two nuclei come into contact, can be considered as analogue to the reverse of the fission process. However, one must keep in mind that these two processes are quite different as for the deformation degrees of freedom. In the exit channel the neck is not disrupted before a large stretching of the fragments has taken place, as opposed to what occurs in the entrance channel. These features are expressed by the existence of two misaligned valleys in the potential energy surface drawn versus the separation and necking parameters. The deep inelastic events are those for which the system is injected from the fusion valley directy into the fission valley without passing the saddle point when this one exists.

The macro nuclear physics which has been very successful in the understanding of the basic features of the fission phenomena is now being widely applied to heavy ion reactions. The knowledge of the nuclear interaction potential between two nuclei is one of the crucial problems in all the treatments. Numerous attempts have been made in which the separation distance of the nuclei is the only considered degree of freedom [7-13]. On the other hand, bunches of potential energy surfaces for complex systems have been computed as a function of separation distance, mass-asymmetry, neck size, eccentricity of the nuclei [14-17].

The dissipation of the collective kinetic energy into internal excitation is treated classically by assuming a relative motion of the undeformed nuclei along classical trajectories in the field of conservative forces and dissipative frictional forces [18-26]. Some improvements have been made in these classical treatments by including important effects such as mass transfer $[23,26]$ and deformation effects $[25,26]$. Furthermore, some microscopic descriptions of energy dissipation have been carried out on light systems $[27-28]$.

Non equilibrium quantum statistical mechanics has also been applied to the deep inelastic phenomena in order to describe the transport or diffusion processes [29-30].

In this paper I would like to survey among 
the experimental results the ones which are more specifically related to the dynamics of the deep inelastic process. In the following report, Moretto will discuss the complementary aspects, dealing with the nucleonic exchange between the nuclei in terms of a diffusion process.

I do not intend to restrict myself to interactions between either light or heavy systems although some differences in the behaviour of heavy systems as compared to lighter ones may have led in the past to classify the corresponding reactions into two well separated categories. Rather, one can show that both reaction processes are very similar in many respects and that a slow evolution from one to the other can be followed. In this evolution the product $z_{1} z_{2}$ of the atomic numbers in the entrance channel does not seem to be the only relevant parameter governing the process. As suggested by recent experiments, the bombarding energy (or the velocity in the relative motion) must also be considered as a determinant factor.

This paper is divided in five sections. In the first one the principal experimental techniques currently used in the identification of deep inelastic reaction products are reviewed. The second part is devoted to a survey of the experimental knowledge with regard to the number of nuclear pieces in the exit channel (the two body question). In the third section the energy damping phenomenon is analyzed in connection with the reaction time (given by the angular distribution) and the nuclear matter exchange. The first results dealing with the excitation energy and spin left into the deep inelastic reaction products are discussed in section 4. Finally the last section considers the relaxation of the neutron excess mode in some details.

\section{EXPERIMENTAL PROCEDURES}

The considerable progress which has been made in the last years in the nucleus identification techniques is largely responsible for the better insight we have gained in the reaction processes. Therefore, I would like to devote this first section to a rapid survey of the different techniques most commonly met in deep inelastic studies $[31]$.

The fundamental parameters one would wish to know are the following :

- the nature of the emitted products (atomic number or/and mass number)
- the angular distribution

- the kinetic energies

- the excitation energies

- the spins.

In most of the experiments the first three characteristics, which are by far the easiest to reach, have been measured and will be considered thereafter. The last two, which require a coincidence measurement between the products and their evaporated particles or $\gamma$-rays, are more difficult to obtain (essentially due to the low counting rate), and so far very few attempts have been made in such a way.

Furthermore coincidence experiments between the massive reaction products are necessary to know whether or not the reaction ends up by only two major bodies in the exit channel.

First, let's examin in some details the atomic number and mass identification techniques. Both determinations require kinetic energy measurements performed either by solid state or gas counters. For masses heavier than mass 50 the energy determination in SSD becomes a worrying problem. An energy defect has been observed with such heavy ions. Charge recombinations, nuclear collisions and other less known effects can be grossly accounted for by empirical methods. Nevertheless improvements should be done in the future in order for the energy resolution not to be the limiting parameter in time of flight measurements. One might hope that gas counters could improve energy resolution.

A- Atomic number identification.

$\left.1^{\circ}\right)$ Te-lescopes $\Delta E-E$.

Due to the difficulties encountered to build thin and homogeneous transmission solid state detectors (SSD), in heavy ion studies the telescopes. are often composed of a gas $\triangle E$ counter associated with a gas or a SSD E-counter. Two types of gas counters are frequently used : proportional counters and ionization chambers. The typical energy resolution in proportional counters is about 5\% [32] and this does not allow to resolve the elements above $\mathrm{Z}=20$. Ionization chambers exhibit a much better resolution $[33-34]$. The effective resolution depends very much on the amount of energy dropped in the counter. Under favorable energy conditions elements up to $Z=50$ can still be resolved [35]. This promising technique is versatile and cheap. It is quite adapted for kinematic measure- 
ments and has been extensively used during the two past years. A typical example of $Z$ identification obtained at Orsay is given in Figure 1 .

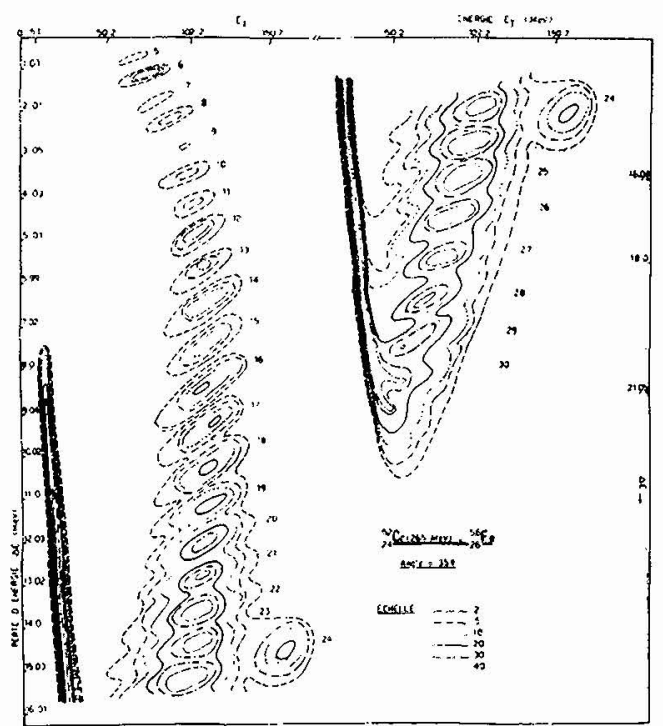

Fig. 1 - Example of 2 identification performed by means of an ionization chamber [75].

$\left.2^{\circ}\right)$ x-rays.

Reaction products can be collected in catchers and $\mathrm{X}$-rays activities are measured of $\mathrm{f}$ line. Difficulties are encountered to determine the absolute yields because a given $Z$ consists of several isotopes each decaying with different half live and with different branching ratios for $\mathrm{K}$ capture yersus $B^{+}$emission, gamma decay versus internal conversion and X-ray fluorescence versus Auger decay. Nevertheless this technique has proved its usefulness in angular distributions. It allows to study either low energy or heavy elements which cannot be identified by the classical telescope $[36-37]$.

B- Mass identification.

$\left.1^{\circ}\right)$ Correlated fragment energy measurements.

The kinetic energies of two correlated fragments are measured by two solid state detectors set at judicious angles. This technique has been extensively applied in fission studies. When a binary split is assumed it is made use of the conservation of both total mass and linear momentum to carry out the individual masses from energy measurements. The method has been utilized in deep inelastic studies on heavy systems $[38-39]$. Furthermore the coincidence requirement allows to test the full momentum transfer and to evaluate the rate of binary splits. However the limited accuracy of the energy measurement leads to large and, in some cases, systematic errors in the mass determination. For very asymmetric splits the method is very poor. Moreover it cannot be used at very forward and backward angles.

$2^{\circ}$ ) Time-of-flight spectrometers.

Presently, the T.0.F. technique seems to be the most common mass identification method [40, 41]. From T.O.F. (i.e. velocity) and energy measurements the mass can be extracted unambiguously. The mass resolution is depending on both velocity and energy resolutions.

For a given time resolution the velocity resolution can be optimized by increasing the flight path at the expense of the geometrical efficiency. However, in deep inelastic studies individual cross sections are often low and the flight path scarcely exceeds $100-150 \mathrm{~cm}$. Therefore, different ways are explored in order to reach the best time resolution. Timing signals are obtained from the following devices :

a solid state detectors.

b thin plastic scintillators associated with photomultipliers.

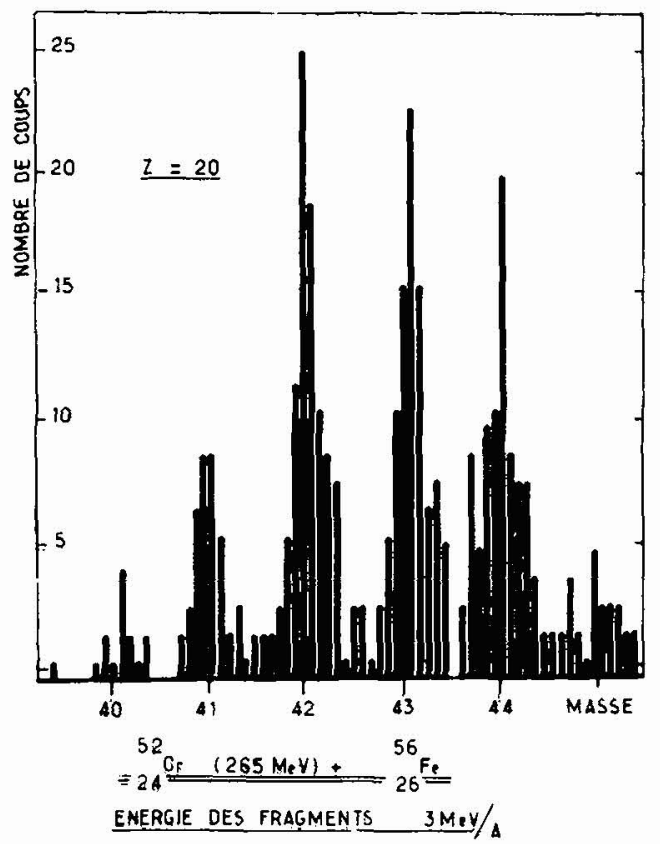

Fig. 2 - Example of mass spectrum obtained with a TOF spectrometer between a plastic scintillator and $a$ SSD with a flight path of about $100 \mathrm{~cm}$ and a time resolution of about 250 ps 775$]$. 
c thin carbon foils associated with electron muitipliers (channel plates) or solid state detectors.

d thin gas counters working in the avalanche mode .

In prificiple all these timing systems can be associated two by two to provide start and stop signals. However, the most comon combinations have been $(a+a),(b+a)$ (examile is given in fig. 2), $(c+a),(c+c)$ and $(d+d)$. The use of a SSD for delivering the stop signal is advantageous since both timing and energy informations are provided by the same counter. On average, when operating under realistic beam conditions the time resolution for most of these systems varies from 150 ps to $300 \mathrm{ps}$. It is difficult to compare the qualities of the different systems since some of them are still in the early stages of their operation.

\section{$\left.3^{\circ}\right)$ Magnetic spectrometers}

Magnetic analysis with simultaneous measurements of particle energy and position in the output focal plane has been currently used in deep inelastic studies [42-43]

This method provides a high mass resolution and permits to remove the elastically scattered ions loading the detector by using the difference of particle magretic rigidities. But this method does not ensure unique identification of particles since particles having the same or very close $\mathrm{q}^{2} / \mathrm{A}$ cannot be separated. These ambiguities are removed by adding a $i$ identification by means of a $\Delta E-E$ telescope. Additional time of flight measurement may be useful to better resolve two neighbour elements with very different masses and close $\mathrm{q}^{2} / \mathrm{A}$.

$C-$ Mass $+Z$ identification.

$\left.1^{\circ}\right)$ Combination of $\triangle E-E$ and TOF techniques.

An example of such a method can be found in ref. [44] where a TOF is measured between a plastic foil scintillator and a SSD. A $\Delta E-i o n i s a-$ tion chamber set in front of the SSD allows to determine the 2 . Corrections are made to account for the slowing down in the gas.

$\left.2^{\circ}\right)$ Combination of magnetic analysis and $\Delta E-E$.

In mass determinations it has been shown why the combination of these two methods was quite necessary to tide over the difficulties due to the different charge states. This technique has proved its high selectivity in the search of isotopes removed from the stability region [2]. Moreover it allows to measure particles emitted very forward by getting rid of the elastically scattered beam. However the high selectivity can also be considered as a disadvantage : in a study of reaction mechanisms, for each detection angle, the magnetic field must be varied several times in order to get the whole energy spectra. (beam time consuming).

$\left.3^{\circ}\right)$ In beam $\gamma$ ray spectroscopy.

The reaction products are identified by the energy of their $\gamma$ transitions as in ref [45]. Some informations about the recoil energies can be reached by means of the Doppler effect. Cross sections and angular distribution cannot be known. This technique could be applied in coincidence in order to identify correlated light and heavy fragments.

$\left.4^{\circ}\right)$ Off-beam $\gamma$ and $\alpha$ spectroscopy

Thick targets in which recoil products are stopped can be chemically processed [46-49]. $\gamma^{-}$ spectroscopy is then applied to the different chemical fractions. A wide survey of reaction products is thus obtained but few informations can be carried out as for the reaction mechanisms.

When utilizing thin targets the recoil products are collected in stacked catchers so that both kinetic energies and angular distributions can be determined after $\gamma$-ray or $\alpha$-ray analysis. This method is of particular interest for studying heavy products, the energy of which is too low for conventional $\triangle E-E$ or TOF identifications to be carried out $[50-51]$.

II. THE DEEP INELASTIC REACTIONS : A TWO-BODY PROCESS.

First of all we must make clear what we mean by a two-body process. Light particles such as neutrons, protons and $\alpha$-particles which can be emitted either during the interaction or after the massive products have flown apart are not taken into account in the product number balance. On the other hand, for easily fissionable targets as $U$, the heavy recoil products may undergo fission. This will not be considered as a true ternary split since the three bodies do appear in sequence : the reaction can be decomposed in two different stages and the first stage corresponds to a purely binary split. 
The binary character of completely damped collisions was suspected without any coincidence measurements just by considering the absolute kinetic energy of the products. Indeed, this energy corresponds roughly to the Coulomb repulsion energy due to the complementary fragment (assuming two spherical nuclei in contact). However this clue cannot be considered as a completely convincing argument for the two following reasons. First, for some mass asymmetric configurations the coulomb energy resulting from the repulsion of two distinct fragments on a third one is not expected to be much different from the one arising in a binary split. Moreover, due to the fragment deformation, the orbital angular momentum and the effects of subsequent evaporation in the fragments, one cannot know accurately what kinetic energy is to be expected from a binary split even though a complete damping of the relative motion is assumed.

Some other hints of the binary character of the deep inelastic reactions were also found in uncorrelated experiments where both light and assumed heavy correlated products were measured. In the study of the $\left({ }^{40} \mathrm{Ca}+{ }^{64} \mathrm{Ni}\right)$ system $[54]$ it was found that, qualitatively, both energy and angular distributions for two assumed correlated products exhibited complementary patterns in the center of mass frame. Moreover, when considering two expected correlated fragments at $90^{\circ} \mathrm{c} \cdot \mathrm{m}$. their mean kinetic energies were found in total agreement with what is required from the momentum conservation. In addition, and within the experimental statistical uncertainties $( \pm 10 \%)$, the cross sections were also found to be in agreement.

More direct evidences of the binary splitting in deep inelastic reactions were clearly stressed in coincidence experiments. According to the nature of the measured parameters we can distinguish different kinds of coincidence experiments.

In fission type experiments [85-39] it was assumed that the process was binary and only the fragment kinetic energies were measured. Assuming furthermore the full momentum transfer and the mass conservation, the individual masses were extracted in applying the momentum conservation law. It was shown that the fragments relative emission angle in the center of mass system was on average $180^{\circ}$ and that the width of the distribution was compatible with distortions effects due to subsequent deexcitation of the fragments by particle evapora- tion. At least $90 \%$ of the events in $\mathrm{Kr}+\mathrm{Bi}$ and $\mathrm{Cu}+\mathrm{Au}$ experiments were reported as binary ones.

In other coincidence experiments, in addition to the kinetic energy measurements, other parameters were measured. These supplementary parameters are not necessary for proving the binary character of the split but they may allow to get some insight into the light particle $(n, p, \alpha)$ emission prior or/and after the split as we shall see in section 4. The way in which such experiments are analyzed depends strongly on the nature of the additional measured parameters. So far we can distinguish three categories :

i) The light fragment atomic number is measured as in the ${ }^{22} \mathrm{Ne}(252 \mathrm{MeV})+{ }^{107-109} \mathrm{Ag}$ experiment carried out at Berkeley [52].

ii) Mass identification is achieved for one fragment and atomic number for the correlated one as in the Heidelberg experiment for the ${ }^{32} \mathrm{~S}(140 \mathrm{MeV})+{ }^{50} \mathrm{Ti}$ system $[71]$.

iii) Mass + atomic number identification for the light fragment and mass identification for the correlated one as in the Orsay experiment : ${ }^{40} \mathrm{Ar}(288$ $\mathrm{MeV})+{ }^{58} \mathrm{Ni}[102]$.

The common result of all these works is, that, for at least $90 \%$ of the events (the experimental limit), the process is binary. Furthermore; so far, to my knowledge there is no reported case of coincidence experiments in which a missing mass amount could not be explained by light particle emission. (The fissioning heavy recoil product being considered as a special case). We shall come back in section 4 to the problem of the particles evaporated by the fragments.

III. THE KINETIC ENERGY DAMPING.

The most striking features revealed in deep inelastic collisions are connected with a large energy damping in the relative motion. As it will be shown in Moretto's paper [52] deep inelastic collisions do not necessarily result in important nuclear matter exchanges and therefore, one cannot rely on the product identity to guess the interaction mechanism. Rather, both energy and angular distributions can better characterize the mechanism. In that respect contour plots giving the yields of the different nuclei as a function of kinetic energy and emission angle appear to be the best way to visualize the whole experimental result. Three typical 

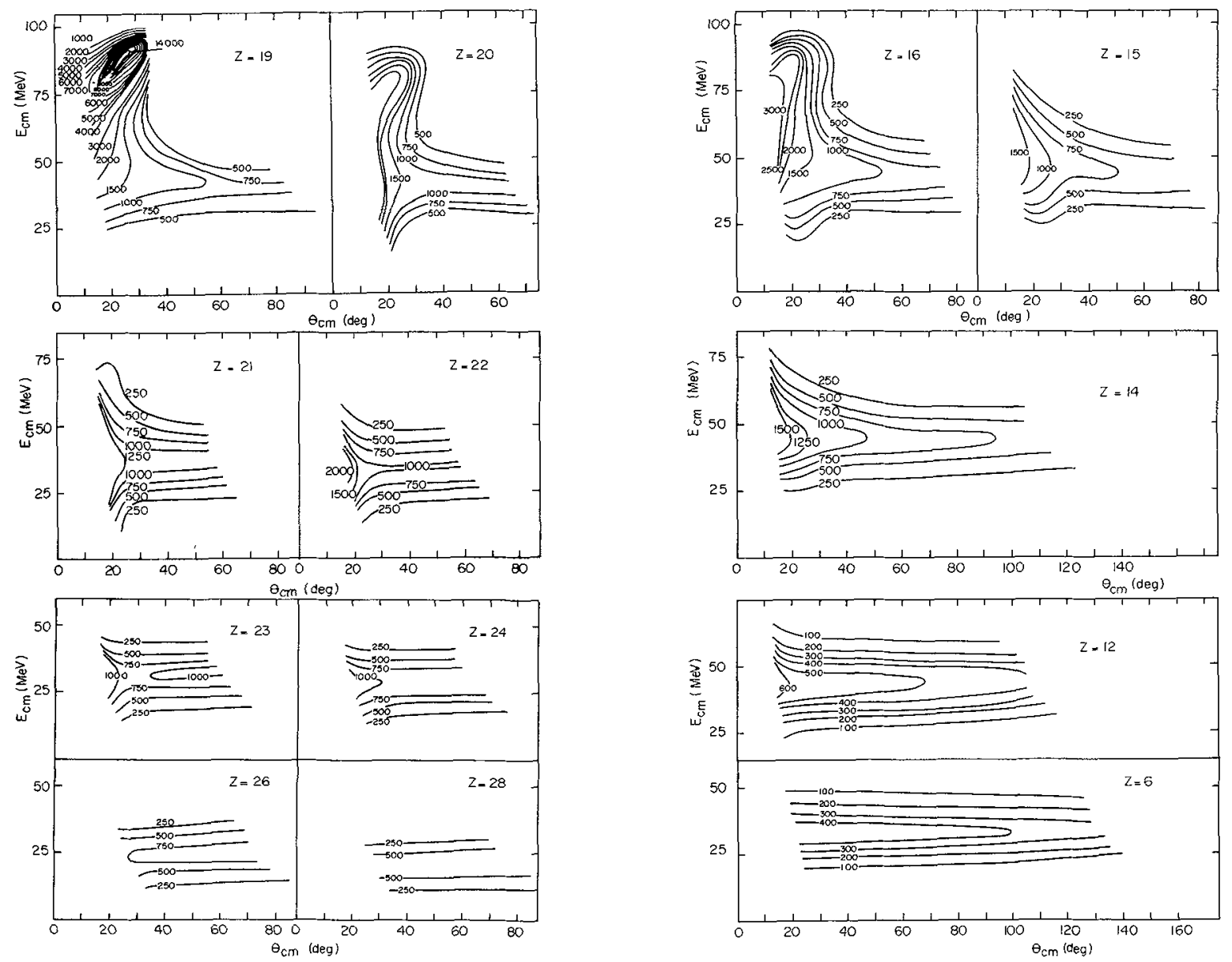

Fig. 3 - Contour plot of the center of mass cross section in the E, $\theta$ plane for different elements in the reaction ${ }^{40} \mathrm{Ar}(280 \mathrm{MeV})+58 \mathrm{Ni}$ [53]. The cross sections are given in $\mu \mathrm{b} / \mathrm{MeV}$.rad.

reactions have been selected in order to give some hints of what can be observed in varying the entrance channel parameters. First, two medium mass similar systems $\left({ }^{40} \mathrm{Ar}+{ }^{58} \mathrm{Ni}\right)$ [53] and $\left({ }^{40} \mathrm{Ca}+{ }^{64} \mathrm{Ni}\right)$ [54] are considered with different bombarding energy conditions (respectively $2.5 \mathrm{~B}$ and $1.5 \mathrm{~B}$, where $\mathrm{B}$ is the interaction barrier). Then a much massive system $\left({ }^{86} \mathrm{Kr}+{ }^{197} \mathrm{Au} ; \mathrm{E}=1.4 \mathrm{~B}\right)[35,55]$ will be surveyed. $\left.1^{\circ}\right){ }^{40} \mathrm{Art}+{ }^{58} \mathrm{Ni}(288 \mathrm{MeV})$ [53].

In figure 3, quite different patterns in the contour plots can be distinguished according to the product identity. Two ridges can be observed in the yield distribution for those nuclei close to the projectile. The high energy ridge extends from Q.E.peak (elastic scattering energy, grazing angle) towards lower energies and smaller an- gles. It seems reasonable to assume that smaller and smaller partial $\&$ waves as compared to $\&$ grazing are involved, leading to a larger and larger overlap of nuclear matter and, hence, to an increasing energy damping and more and more forward distorded trajectories as compared to purely Coulomb ones. The corresponding collisions might be of the hit and run type defined by Swiatecki [56]. The continuation of this ridge could probably lead to negative deflection angles. As pointed out earlier by Wilczynski [57], due to symmetry of the phenomenon around $0^{\circ}$, the extension of the previous ridge could be the ridge observed at positive angles with continuously decreasing energy. In such a picture and assuming the classical deflection function as meaningful (this may be questionable when low 2 waves are con- 
sidered) one would get a pattern as described in figure 4. A single rainbow angle arises slightly forward of the grazing angle with a corresponding concentration of cross section as suggested in the $K$ contour plot, rapidly decreasing backward and slowly decreasing forward.

Another alternative explanation sketched in figure 4 has been suggested by Deubler and Dietrich [25]. According to the dynamical calcula-

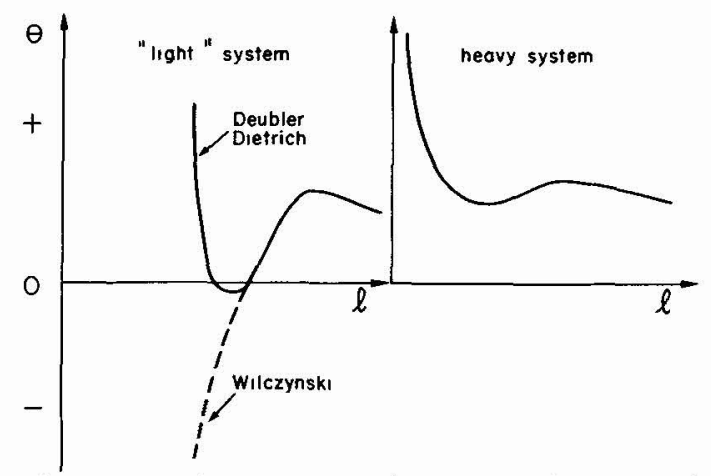

Fig. 4 - Left - Schematic deflection functions as suggested by Wilczynski on the one hand and by Deubler-Dietrich on the other hand.

Right- Possible deflection function which could explain the $\theta$-focusing effect observed in the study of heavy systems.

tions carried out by these authors on the Ar+Th system a second rainbow angle arises near $0^{\circ}$. One can assume the same pattern for a system like Ar+Ni with some accumulation of cross section in the very forward direction. However there is no way, in the present experimental data, to decide which one of the Wilczynski or Deubler-Dietrich explanation is the right one. In that respect additional measurements close to $0^{\circ}$ might be very valuable.

Anyway, there is definitely a continuous evolution between quasi elastic phenomena and completely damped ones. The collisions labelled by Swiatecki as grazing collisions, hit and run collisions and completely damped collisions are both involved in the formation of nuclei such as $\mathrm{Cl}$, $\mathrm{Ar}$ and $K$.

The previous picture can be precised in studying the contour plot patterns for the different isotopes of a given element near the projectile (fig. 5). For example, the most abundant $\mathrm{K}$ isotope is ${ }^{41} \mathrm{~K}$. It corresponds to the simplest exchange : a single proton pick-up by the projectile. As we look at isotopes for which more and more complex nucleon exchanges are involved we do
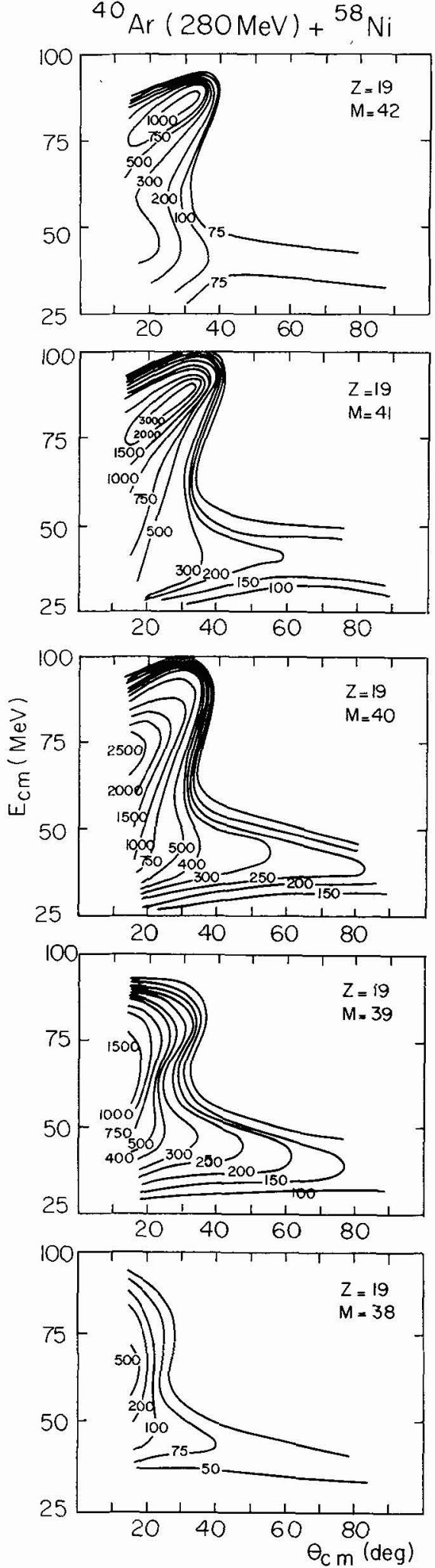

Fig. 5 - Contour plot of the center of mass cross section in the $\mathrm{E}, \theta$ plane for $\mathrm{K}$ isotopes in the reaction $40 \mathrm{Ar}(280 \mathrm{MeV})+58 \mathrm{Ni}$ [53]. The cross sections are given in $\mu \mathrm{b} / \mathrm{MeV}$. rad. 
see a decrease in the peak intensity as well as the location of this peak is shifted towards smaller angle and energy values. The slow transition from grazing collisions to inner ones is well perceived, however, as it is a continuous process, one cannot set any boundary between grazing, hit and run and deep inelastic collisions.

The same striking evolution can be followed considering elements farther and farther removed from the projectile (fig. 3). Progressively, grazing collisions contribute less and less in the formation of either lighter or heavier elements as compared to the projectile. Then, the same trend is true considering the intermediate hit and run collisions. "The average interaction time becomes larger and larger as inner and inner $\&$ waves are involved. As a result the yields are more spread all over the space.

For the strongly damped phenomena the interaction time is large enough for the transitory existence of a "composite" system [58] or "intermediate complex" [29] or "double nuclear system" [59] to be considered. Either, this composite system does survive long enough for the two nuclei to fuse first (complete lost of their identity) and finally reach the complete equilibrated compound nucleus stage. or, the disruption occurs after the system has rotated during a fraction of period or even several periods. When the split occurs in the completely equilibrated compound nucleus, then, a true fission process is observed. There is a continuity in the whole process described above and $i t$ is quite difficult in many cases to distinguish a true fission phenomenon (C.N. fission with high excitation energy and angular momentum) from a fission before complete equilibrium has been reached. A good example is given by the $Z=6$ contour plot pattern, in which the angular distribution is only slightly more forward peaked than the one expected in a true fission process. $\left.2^{\circ}\right){ }^{40} \mathrm{Ca}{ }^{64} \mathrm{Ni}(182 \mathrm{MeV})$ [54] (Fig. 6)

When comparing this system with the previous one (very similar as far as the size of interacting nuclei is concerned) it is quite instructive to see the effects of bombarding energy on the contour plot patterns (fig. 6). Due to the smaller energy difference between the entrance and the fully damped exit channel ( $0.5 \mathrm{~B}$ instead of $1.5 \mathrm{~B}$ ), the appearance of the two ridges is nearly completely masked. Instead, as shown for $Z=21$ a broad distribution is observed. Nevertheless there are some clues indicating that the behavior observed at high bombarding energy remains valid at low energy. The cross section is decreasing forward as well as a flat ridge is extending further backward. However near (and forward of) the grazing angle it seems unrealistic to try to evaluate the two contributions as it could be done at high bombarding energy.

As we consider light reaction products

(from $Z=18$ to $Z=12$ ) a nice smooth transition can be observed from a side peaking to a forward peaking. At the same time the kinetic energy of the maximum progressively is getting closer the one measured at large angles. At first glance all these characteristics resemble very much what has been seen in the study of more massive systems. $\left.3^{\circ}\right){ }^{86} \mathrm{Kr}+{ }^{197} \mathrm{Au}(620 \mathrm{MeV})[35,55]$ (fig. 7)

The bombarding energy is approximately $1.4 \mathrm{~B}$ and, in this respect, the entrance channel conditions are approximately the same as for the (Ca $+\mathrm{Ni}$ ) system. Qualitatively the same evolution from side peaking to forward peaking is observed as one considers nuclei more and more removed from the projectile. There is also some evidence for the different product cross sections not to be completely negligeable near $0^{\circ}$. However; the relative cross section in the forward direction as compared to the one measured at the maximum of the distribution is much smaller for the heavy'system than for the light one indicating a stronger focusing in the yield distribution.

This main difference in the behavior of light and heavy systems is rather unexpected.

Indeed, it is known that for light systems an important part of the reaction cross section is found in the compound nucleus formation. This is opposite to what has been seen in heavy nuclei interaction. Therefore the $\ell$ wave range leading to other channels than C.N. is much wider for heavy systems than for light ones and hence, the yields are expected to be more scattered in the space.

The study of the product distribution FWHM can help to understand this behavior. If we assume the life time of the system as a decreasing function of the impact parameter and the product distribution FWHM as an increasing function of the lifetime then the FWHM is a decreasing function of the impact parameter (or \&). For the $\mathrm{Kr}+\mathrm{Au}$ for example $\mid 35$ ! it has been pointed out that for interme- 

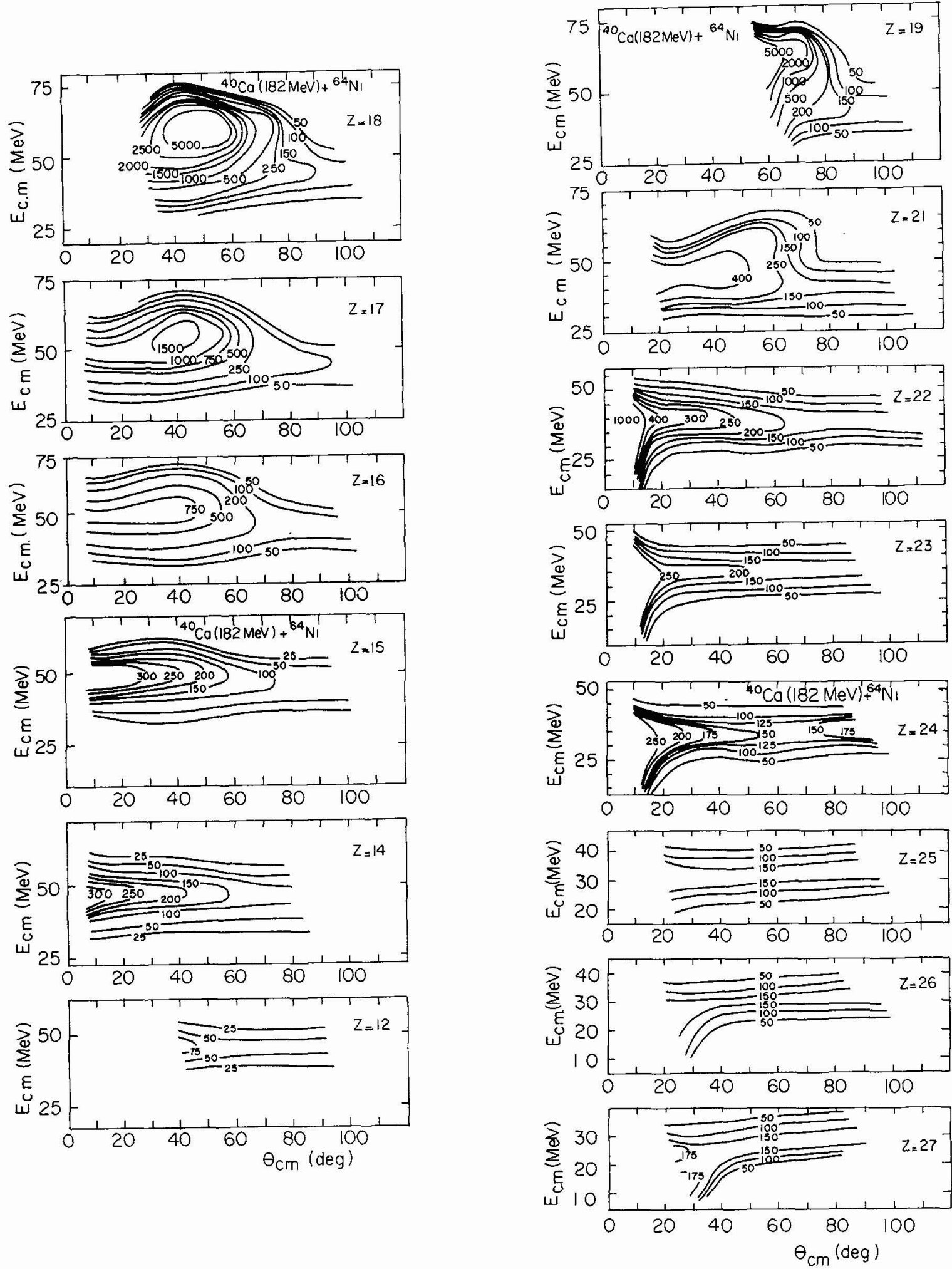

Fig. 6 - Contour plot of the center of mass cross section in the E, $\theta$ plane for different elements in the reaction ${ }^{40} \mathrm{Ca}(182 \mathrm{MeV})+{ }^{6}{ }^{4} \mathrm{Ni}[54]$. The cross sections are given in $\mu b / \mathrm{MeV} \cdot \mathrm{rad}$. 


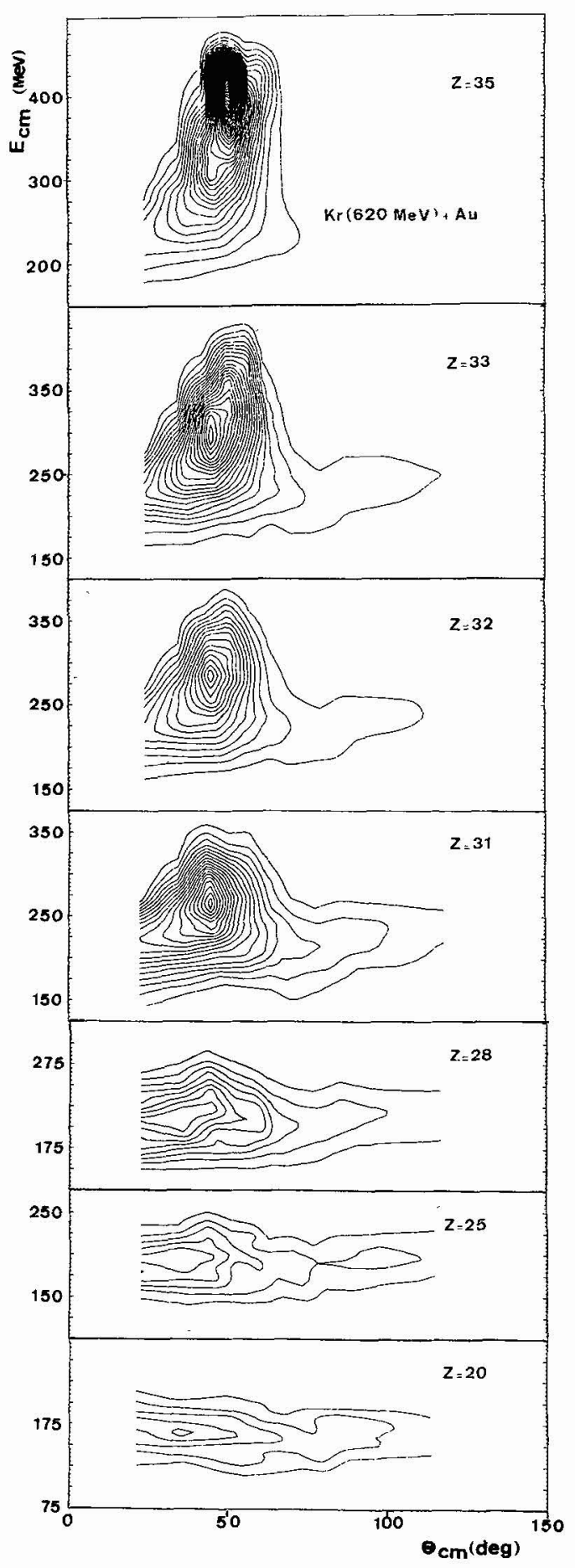

Fig. 7 - Contour plot of the center of mass cross section in the $\mathrm{E}, \theta$ plane for some elements with atomic numbers below the projectile in the ${ }^{86} \mathrm{Kr}(620 \mathrm{MeV})+{ }^{197} \mathrm{Au}$ studied at Berkeley [35]. The contour lines are equally spaced with the following steps :

$-\mathrm{Z}=20 \Delta^{2} \sigma / \partial \theta \partial \mathrm{E}=5 \mu \mathrm{b} / \mathrm{rad} . \mathrm{MeV}$

$-Z=25 \quad "=20 "$

$-Z=28$

$-Z=31$

$-\mathrm{z}=32$

$-z=33$

$-Z=35$

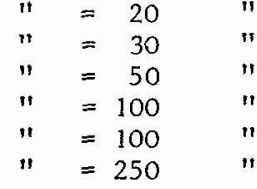

diate angles the FWHM was the smallest (large $\ell$ ), for backward angles the FWHM was the largest (smaIl l) and for forward angles the FWHM was intermediate (intermediate $\ell$ ). This gives rise to the two rainbow angles deflection function as shown in figure 4 , with the cross section focused in a narrow angular range.

Now, if one considers intermediate systems between the ones surveyed so far in this section (1ike $(\mathrm{Ar}+\mathrm{Au})[60-61],(\mathrm{Cu}+\mathrm{Au})[62],(\mathrm{Cu}+\mathrm{Sm})$ [51]) their behaviors seem to depend strongly on the bombarding energy (fig. 8). At low bombárding

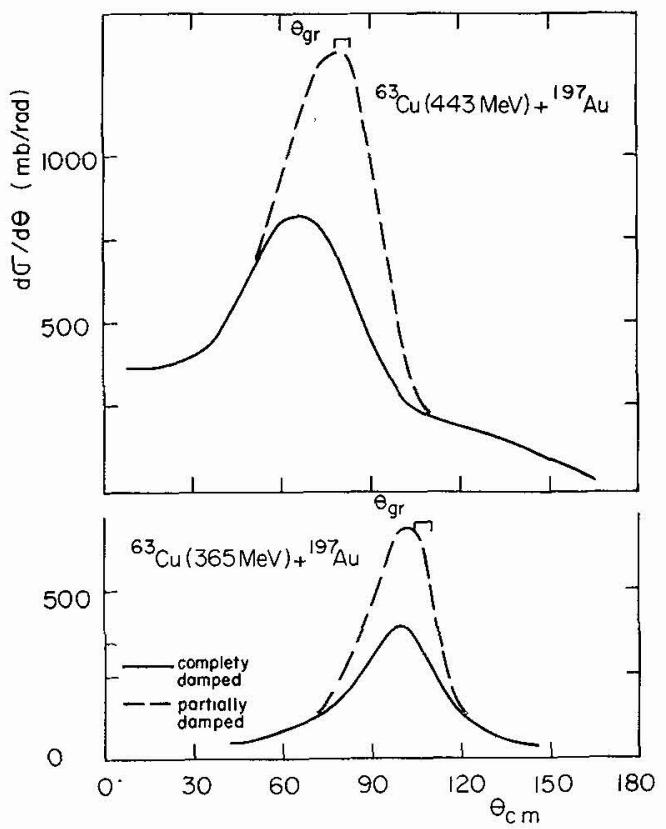

Fig. 8 - Angular distributions for quasi-Cu reaction products in the system ${ }^{63} \mathrm{Cu}+197 \mathrm{Au}$ at $365 \mathrm{MeV}$ and $443 \mathrm{MeV}$ bombarding energy.

energy the angular distributions appear to be rather of the $(\mathrm{Kr}+\mathrm{Au})$ type whereas at high energy they resemble more the ones observed in the (Ar+Ni) study. An intermediate pattern has also been pointed out by Wolf et al [63] for the $\mathrm{Kr}+\mathrm{Ho}$ system at 714 $\mathrm{MeV}$, by Webb et al [64] for the $\mathrm{Kr}+\mathrm{La}$ system at 710 MeV and by Berlanger et al [65] for the Cu+Nb system at $280 \mathrm{MeV}$. So, it is clearly seen that the size of the nucleides and their mass asymmetry in the entrance channel are not the only relevant parameters influencing the interaction. A decrease in the size of the interacting nucleides seems to have to some extend the same effects as an increase of the relative velocity for two heavy interacting nucleides. 
To classify the studied systems, a parameter similar to the Sommerfeld parameter $n^{\prime}$ $=\mathrm{z}_{\mathrm{p}} \mathrm{z}_{\mathrm{T}} \mathrm{e}^{2} / \mathrm{hv}^{\prime}$, where $\mathrm{v}^{\prime}$ is the relative velocity when the two nucleides come in contact (corresponding to $\mathrm{E}-\mathrm{B}$ ), might be more relevant than the usual discrimination based on the interacting nucleus sizes. It can be noticed that the Sommerfeld like parameter $\eta^{\prime}$ is proportional to the ratio of a Coulomb force $z_{1} z_{2} e^{2} /\left(r_{1}+r_{2}\right)^{2}$ to a friction force if the later is expressed as $F=-\mathrm{KV}^{*} / \mathrm{r}_{1} \mathrm{r}_{2}$ (this expression is similar to the one proposed by Tsang [10] with the nuclear densities $\rho$ proportional to $1 / \mathrm{r}$ which is a reasonable assumption in the nuclear tails).

Thus, the reaction mechanism seems to be strongly influenced by the delicate balance between the coulomb force and the friction force. For a strong Coulomb force and comparatively small friction force (this is the example of heavy nucleides interacting near the Coulomb barrier and hence with small v') the dynamics appears to be dominated by Coulomb (short interaction time). Conversely for light systems at high bombarding energy the Coulomb effects are washed out by the friction force (1arger interaction time).

I have tried to get together in Table I some systems for which the deep inelastic collisions have been studied by measuring the light reaction products. The bombarding energies are compared to the interaction barriers calculated within the framework of the energy density formalism using the sudden approximation [12]. In heavy combinations $\left(z_{p} z_{t}>2800\right)$ for which the barrier is no longer existing but is replaced by a plateau, the height of this plateau has been estimated. It can be seen that most of the experiments have been done at $1.3<\mathrm{E}$ $<1.7 \mathrm{~B}$. It seems to me that a lot could be learned from all these systems if extensive contour plots were available for the different reaction products. Numerous informations are contained in such graphs, and, furthermore, this could allow the different models to be easily tested.

From the available data, a continuous evolution can be quantitatively depicted as a function of the Sommerfeld-like parameter $\eta^{\prime}$ as follows :

$$
\text { - for low } \eta^{\prime} \text { values [approximately } \eta^{k}<150-200 \text { ] }
$$
the angular distribution are rather very broad with their maximum peaked well forward the grazing angle (orbiting picture) ;
- for large $\eta^{\prime}$ values [approximately $\eta^{\prime}>250-300$ ] most of the cross section is focused close to the grazing angle with an increase in the focusing phenomenon as $n^{\prime}$ increases.

- for intermediate $v^{\prime}$ values there is a transition region where orbiting and focussing processes have somewhat comparable intensities.

If this systematic were true, (Kr+Bi) experiments at $10 \mathrm{MeV}$ per nucleon bombarding energy would lead to a dominant orbiting picture for the reaction products and $\mathrm{Kr}(450 \mathrm{MeV})+\mathrm{Ag}$ on the contrary would show a dominant focusing effect.
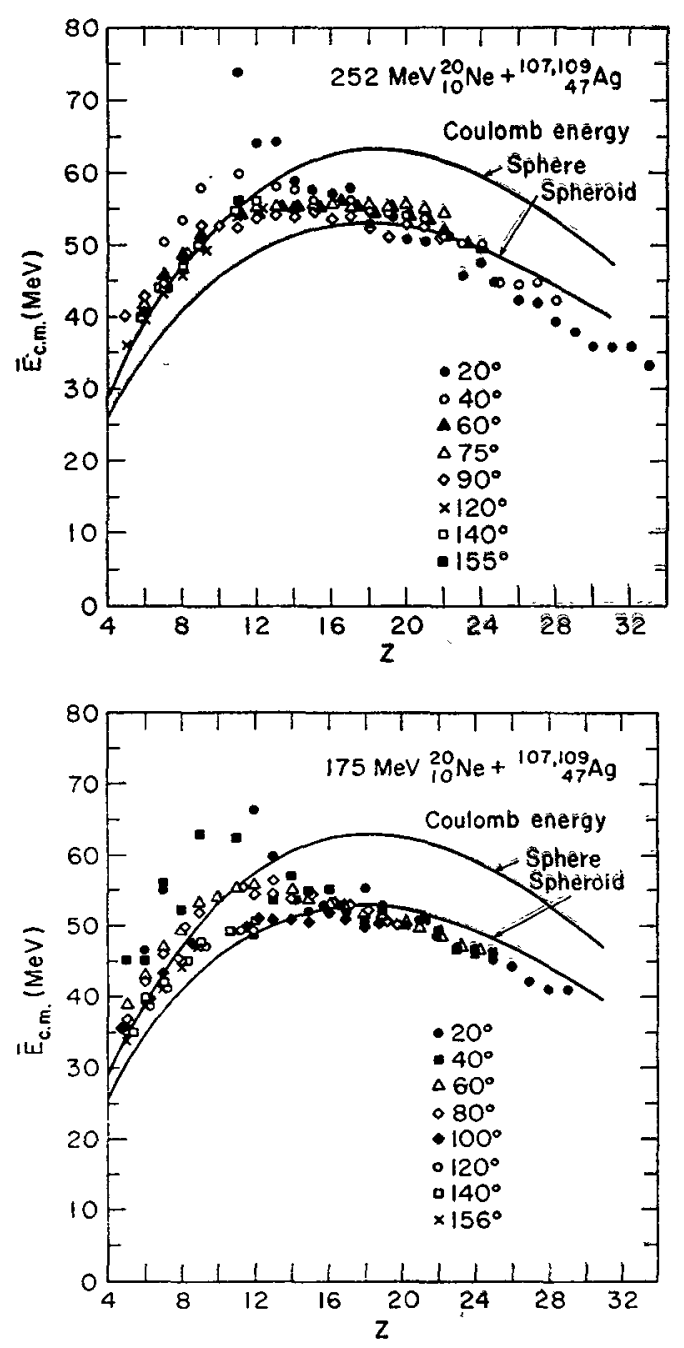

Fig. 9 - Average c.m. kinetic energies as a function of $Z$ for various $1 \mathrm{ab}$ angles without any correction for light particle evaporation. The Coulomb energy is given for two spheres and two spheroids at equilibrium deformation. The radius parameter is $r_{0}=1.224$ and the nuclei are separated by $2.0 \mathrm{fm}[73]$. 


\begin{tabular}{|c|c|c|c|c|c|c|c|c|c|}
\hline$\overline{\text { SYSTEM }}$ & $\overline{p^{\varepsilon} t}$ & $\mathrm{M}_{\mathrm{H}} / \mathrm{M}_{\mathrm{L}}$ & $\begin{array}{c}\mathrm{B} \\
(\mathrm{MeV})\end{array}$ & $\begin{array}{c}E \mathrm{~Eb} \\
(\mathrm{MeV})\end{array}$ & ${ }^{E} \mathrm{c}, \mathrm{m} \cdot \overline{\mathrm{B}}$ & $n$ & $n^{\prime}$ & ${ }^{1} \mathrm{~B}$ & ref. \\
\hline & & & & 100 & $6 \cdot 3$ & $4 \cdot 3$ & $4 \cdot 7$ & 39 & {$[66]$} \\
\hline${ }^{12} \mathrm{C}+{ }^{27} \mathrm{AI}$ & 78 & 2.2 & 11 & 180 & 6.4 & $3 \cdot 2$ & $3 \cdot 4$ & 54 & {$[66]$} \\
\hline${ }^{16} \mathrm{O}+{ }^{27} \mathrm{AI}$ & 104 & 1.7 & 15 & $\begin{array}{r}90 \\
100\end{array}$ & $\begin{array}{l}3.7 \\
4.2\end{array}$ & $\begin{array}{l}6.9 \\
6.5\end{array}$ & $\begin{array}{l}8 \cdot 1 \\
7 \cdot 5\end{array}$ & $\begin{array}{l}37 \\
40\end{array}$ & $\begin{array}{l}{\left[\begin{array}{ll}6 & 7\end{array}\right]} \\
{\left[\begin{array}{ll}6 & 7\end{array}\right]}\end{array}$ \\
\hline${ }^{12} \mathrm{C}+{ }^{89} \mathrm{Y}$ & 234 & $7 \cdot 4$ & 31 & $\begin{array}{l}107 \\
197\end{array}$ & $\begin{array}{l}3.0 \\
5.6\end{array}$ & $\begin{array}{r}12.4 \\
9.1\end{array}$ & $\begin{array}{l}15 \cdot 1 \\
10 \cdot 0\end{array}$ & $\begin{array}{l}54 \\
82\end{array}$ & $\begin{array}{l}{[68]} \\
{\left[\begin{array}{l}68 \\
{[}\end{array}\right]}\end{array}$ \\
\hline${ }^{12} \mathrm{C}+{ }^{98} \mathrm{Mo}$ & 252 & 8.2 & 33 & $\begin{array}{l}107 \\
197\end{array}$ & $\begin{array}{l}2 \cdot 9 \\
5 \cdot 3\end{array}$ & $\begin{array}{r}13.3 \\
9.8\end{array}$ & $\begin{array}{l}16.5 \\
10.8\end{array}$ & $\begin{array}{l}55 \\
84\end{array}$ & $\begin{array}{l}{\left[\begin{array}{ll}6 & 8\end{array}\right]} \\
{\left[\begin{array}{ll}6 & 8\end{array}\right]}\end{array}$ \\
\hline $12 \mathrm{C}+107-109 \mathrm{Ag}$ & 282 & 9.0 & 37 & $\begin{array}{l}86 \\
107 \\
197\end{array}$ & $\begin{array}{l}2.1 \\
2.6 \\
4.8\end{array}$ & $\begin{array}{l}16.6 \\
14.9 \\
11.0\end{array}$ & $\begin{array}{l}23.0 \\
19.0 \\
12.4\end{array}$ & $\begin{array}{l}45 \\
55 \\
84\end{array}$ & 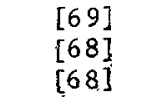 \\
\hline${ }^{12} \mathrm{C}+116 \mathrm{Sn}$ & 300 & 9.7 & 39 & $\begin{array}{l}107 \\
197\end{array}$ & $\begin{array}{l}2 \cdot 5 \\
4.6\end{array}$ & $\begin{array}{l}15.8 \\
11.6\end{array}$ & $\begin{array}{l}20.4 \\
14.8\end{array}$ & $\begin{array}{l}55 \\
85\end{array}$ & $\begin{array}{l}{[68]} \\
{[68]}\end{array}$ \\
\hline $1{ }^{4} \mathrm{~N}+107-109 \mathrm{Ag}$ & 329 & 7.7 & 43 & $\begin{array}{r}78 \\
100 \\
113 \\
160 \\
250\end{array}$ & $\begin{array}{l}1 \cdot 8 \\
2 \cdot 1 \\
2 \cdot 3 \\
3 \cdot 3 \\
5 \cdot 1\end{array}$ & $\begin{array}{l}22 \cdot 0 \\
19 \cdot 3 \\
18 \cdot 2 \\
15 \cdot 3 \\
12.3\end{array}$ & $\begin{array}{l}35.8 \\
26.8 \\
24.1 \\
18.3 \\
13.7\end{array}$ & $\begin{array}{r}40 \\
53 \\
59 \\
78 \\
104\end{array}$ & $\begin{array}{r}{[4]} \\
{\left[\begin{array}{l}7 \\
0\end{array}\right]} \\
{[4]} \\
{[70]} \\
{\left[\begin{array}{ll}7 & 0\end{array}\right]}\end{array}$ \\
\hline${ }^{32} \mathrm{~S}+{ }^{50} \mathrm{Ti}$ & 352 & 1.6 & 49 & 140 & $1 \cdot 7$ & 26.5 & 40.7 & 55 & {$\left[\begin{array}{ll}7 & 1\end{array}\right]$} \\
\hline${ }^{40} \mathrm{Ca}+{ }^{40} \mathrm{Ja}$ & 400 & $1: 0$ & 56 & 278 & $2 \cdot 5$ & 23.9 & 30.9 & 84 & {$\left[\begin{array}{ll}7 & 2\end{array}\right]$} \\
\hline $20 \mathrm{Ne}+207-109 \mathrm{Ag}$ & 470 & $5 \cdot 4$ & 60 & $\begin{array}{l}175 \\
252\end{array}$ & $\begin{array}{l}2.5 \\
3.6\end{array}$ & $\begin{array}{l}25.0 \\
20.8\end{array}$ & $\begin{array}{l}32 \cdot 4 \\
24 \cdot 5\end{array}$ & $\begin{array}{r}86 \\
113\end{array}$ & $\begin{array}{l}{\left[\begin{array}{ll}7 & 3\end{array}\right]} \\
{\left[\begin{array}{ll}7 & 3\end{array}\right]}\end{array}$ \\
\hline${ }^{12} \mathrm{C}+{ }^{197} \mathrm{Au}$ & 474 & 16.4 & 56 & $\begin{array}{l}107 \\
125 \\
197\end{array}$ & $\begin{array}{l}1.8 \\
2.1 \\
3.3\end{array}$ & $\begin{array}{l}25.0 \\
23 \cdot 1 \\
18.4\end{array}$ & $\begin{array}{l}37 \cdot 5 \\
31 \cdot 9 \\
22 \cdot 0\end{array}$ & $\begin{array}{l}55 \\
65 \\
96\end{array}$ & $\begin{array}{l}{[68]} \\
{[74]} \\
{[68]}\end{array}$ \\
\hline${ }^{40} \mathrm{Ar}+{ }^{58} \mathrm{NI}$ & 504 & $1 \cdot 5$ & 67 & 280 & $2 \cdot 5$ & 30.0 & $38 \cdot 8$ & 105 & {$[44,53]$} \\
\hline${ }^{40} \mathrm{Ca}+{ }^{64} \mathrm{Ni}$ & 560 & 1.6 & 74 & 182 & 1.5 & $41 \cdot 4$ & $71 \cdot 1$ & 67 & {$[54]$} \\
\hline${ }^{52} \mathrm{Cr}+{ }^{56} \mathrm{Fe}$ & 624 & $1 \cdot 1$ & 82 & 270 & 1.7 & $43 \cdot 1$ & 67.0 & 90 & {$[75]$} \\
\hline${ }^{160} \mathrm{O}+197 \mathrm{Au}$ & 632 & $12 \cdot 3$ & 74 & $\begin{array}{l}135 \\
166\end{array}$ & $\begin{array}{l}1.7 \\
2.1\end{array}$ & $\begin{array}{l}34 \cdot 2 \\
30 \cdot 9\end{array}$ & $\begin{array}{l}53.5 \\
42.8\end{array}$ & $\begin{array}{l}68 \\
85\end{array}$ & $\begin{array}{l}774] \\
{[74]}\end{array}$ \\
\hline${ }^{40} \mathrm{Ar}+107-109 \mathrm{Ag}$ & 846 & 2.7 & 104 & $\begin{array}{l}16.9 \\
288 \\
340\end{array}$ & $\begin{array}{l}1 \cdot 2 \\
2 \cdot 0 \\
2 \cdot 4\end{array}$ & $\begin{array}{l}64.9 \\
51.6 \\
47.5\end{array}$ & $\begin{array}{r}165.1 \\
72.6 \\
62.3\end{array}$ & $\begin{array}{r}55 \\
131 \\
152\end{array}$ & $\begin{array}{l}{\left[\begin{array}{ll}7 & 6\end{array}\right]} \\
{\left[\begin{array}{ll}7 & 7\end{array}\right]} \\
{\left[\begin{array}{ll}7 & 7\end{array}\right]}\end{array}$ \\
\hline${ }^{22} \mathrm{Ne}+232 \mathrm{Th}$ & 900 & 10.5 & 104 & 174 & 1.5 & 50.4 & 85.7 & 86 & {$[78]$} \\
\hline${ }^{40} \mathrm{Ar}+12 \mathrm{l}-123 \mathrm{Sb}$ & 918 & 3.0 & 112 & $\begin{array}{l}282 \\
340\end{array}$ & $\begin{array}{l}1 \cdot 9 \\
2 \cdot 3\end{array}$ & $\begin{array}{l}54.5 \\
49.6\end{array}$ & $\begin{array}{l}79 \cdot 3 \\
66 \cdot 1\end{array}$ & $\begin{array}{l}132 \\
159\end{array}$ & 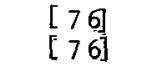 \\
\hline${ }^{86} \mathrm{Kr}+{ }^{63^{-65}} \mathrm{Cu}$ & 1044 & $1 \cdot 3$ & 127 & $\begin{array}{l}494 \\
604\end{array}$ & $\begin{array}{l}1.7 \\
2.0\end{array}$ & $\begin{array}{l}68 \cdot 6 \\
62 \cdot 0\end{array}$ & $\begin{array}{r}108 \cdot 7 \\
87 \cdot 0\end{array}$ & $\begin{array}{l}132 \\
165\end{array}$ & $\begin{array}{l}{\left[\begin{array}{l}7 \\
{[}\end{array}\right]} \\
{[76]}\end{array}$ \\
\hline${ }^{6}{ }^{3} \mathrm{Cu}+{ }^{93} \mathrm{Nb}$ & 1189 & $1 \cdot 5$ & 143 & 280 & $1 \cdot 2$ & $88 \cdot 8$ & $234 \cdot 2$ & 68 & {$[65]$} \\
\hline${ }^{40} \mathrm{Ar}+197 \mathrm{Au}$ & 1422 & $4 \cdot 9$ & 159 & $\begin{array}{l}204 \\
220 \\
250 \\
288 \\
340\end{array}$ & $\begin{array}{l}1.05 \\
1.15 \\
1.3 \\
1.5 \\
1.8\end{array}$ & $\begin{array}{l}99.4 \\
95.5 \\
89.6 \\
83.6 \\
76.8\end{array}$ & $\begin{array}{l}408.6 \\
263.7 \\
184.6 \\
144.5 \\
116.0\end{array}$ & $\begin{array}{r}47 \\
73 \\
104 \\
133 \\
166\end{array}$ & 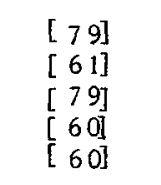 \\
\hline${ }^{40} \mathrm{Ar}+232 \mathrm{Th}$ & 1620 & 5.8 & 184 & $\begin{array}{l}297 \\
388\end{array}$ & $\begin{array}{l}1.4 \\
1.8\end{array}$ & $\begin{array}{l}93.7 \\
82.0\end{array}$ & $\begin{array}{l}179.4 \\
123.0\end{array}$ & $\begin{array}{l}127 \\
186\end{array}$ & $\begin{array}{l}{\left[\begin{array}{ll}8 & 0\end{array}\right.} \\
{\left[\begin{array}{ll}8 & 0\end{array}\right]}\end{array}$ \\
\hline${ }^{86} \mathrm{Kr}+107 \cdot 109 \mathrm{Ag}$ & 1692 & $1 \cdot 3$ & 194 & 606 & 1.7 & 100.5 & 154.3 & 207 & {$\left[\begin{array}{ll}8 & 1\end{array}\right]$} \\
\hline${ }^{86} \mathrm{Kr}+2{ }^{39} \mathrm{La}$ & 2052 & 1.6 & 228 & 710 & 1.8 & 112.5 & $162 \cdot 3$ & 274 & {$\left[\begin{array}{ll}6 & 4\end{array}\right]$} \\
\hline${ }^{63} \mathrm{Cu}+186 \mathrm{~W}$ & 2146 & 3.0 & 237 & 395 & 1.2 & 135.0 & 304.4 & 137 & {$[82]$} \\
\hline
\end{tabular}




\begin{tabular}{|c|c|c|c|c|c|c|c|c|c|c|}
\hline SYSTEM & $\mathrm{z}^{z} t$ & ${ }^{M}{ }^{1 / M} L$ & & $\begin{array}{c}\bar{B} \\
(\mathrm{MeV})\end{array}$ & $\begin{array}{l}E_{1 \mathrm{ab}} \\
(\mathrm{MeV})\end{array}$ & $\mathrm{E}_{\mathrm{c} . \mathrm{m} \cdot / \mathrm{B}}$ & $\eta$ & $n^{\prime}$ & $I_{B}$ & ref. \\
\hline${ }^{63} \mathrm{Cu}+{ }^{197} \mathrm{Au}$ & 2291 & 3.1 & & 248 & $\begin{array}{l}365 \\
443\end{array}$ & $\begin{array}{l}1.1 \\
1.3\end{array}$ & $\begin{array}{l}149.8 \\
136.2\end{array}$ & $\begin{array}{l}463.0 \\
267.3\end{array}$ & $\begin{array}{l}99 \\
171\end{array}$ & $\begin{array}{l}{\left[\begin{array}{lll}8 & 3\end{array}\right]} \\
{\left[\begin{array}{lll}6 & 6 & 2\end{array}\right]}\end{array}$ \\
\hline${ }^{84} \mathrm{Kr}+{ }^{165} \mathrm{Ho}$ & 2412 & 1.9 & & 267 & 714 & 1.8 & 131.9 & 201.0 & 279 & {$\left[\begin{array}{lll}6 & 63 & ]\end{array}\right]$} \\
\hline${ }^{36} \mathrm{X}^{\mathrm{C}}+107-109 \mathrm{Ag}$ & 2538 & 1.3 & & 276 & 1124 & 1.8 & 139.0 & 208.2 & 304 & {$\left[\begin{array}{ll}6 & 3\end{array}\right]$} \\
\hline${ }^{86} \mathrm{Kr}+181 \mathrm{Ta}$ & 2628 & 2.1 & & 288 & 620 & 1.5 & 154.2 & 275.0 & 235 & {$\left[\begin{array}{lll}8 & 84\end{array}\right]$} \\
\hline${ }^{6} \mathrm{Kr}+{ }^{197} \mathrm{Au}$ & 2844 & $2 \cdot 3$ & ح & 307 & 620 & 1.4 & 166.8 & 310.0 & 233 & {$\left[\begin{array}{ll}35 & ]\end{array}\right.$} \\
\hline${ }^{84} \mathrm{Kr}+209 \mathrm{Bi}$ & 2988 & 2.5 & $\sim$ & 315 & $\begin{array}{l}505 \\
525 \\
598 \\
714\end{array}$ & $\begin{array}{l}1.15 \\
1.20 \\
1.35 \\
1.60\end{array}$ & $\begin{array}{l}192.1 \\
188.4 \\
178.5 \\
163.5\end{array}$ & $\begin{array}{l}543.3 \\
474.3 \\
352.0 \\
266.6\end{array}$ & $\begin{array}{l}142 \\
162 \\
220 \\
291\end{array}$ & $\begin{array}{l}{\left[\begin{array}{lll}3 & 8 & \end{array}\right]} \\
{\left[\begin{array}{lll}8 & 5\end{array}\right]} \\
{\left[\begin{array}{lll}3 & 9\end{array}\right]} \\
{\left[\begin{array}{lll}6 & 6\end{array}\right]}\end{array}$ \\
\hline $136 \mathrm{Xe}+159 \mathrm{~Tb}$ & 3510 & 1.2 & 2 & 366 & 979 & 1.4 & 247.5 & 372.0 & 301 & {$\left[\begin{array}{lll}8 & 6 & 6\end{array}\right]$} \\
\hline $236 \mathrm{Xe}+{ }^{281} \mathrm{Ta}$ & 3942 & 1.3 & $\sim$ & 409 & 1120 & 1.6 & 216.5 & 360.9 & 375 & {$\left[\begin{array}{ll}87 & ]\end{array}\right.$} \\
\hline${ }^{136} \mathrm{Xe}+{ }^{197} \mathrm{Au}$ & 4266 & 1.4 & $\sim$ & 431 & 979 & $1 \cdot 3$ & 290.4 & 495.5 & 310 & {$\left[\begin{array}{lll}8 & 6 & 6\end{array}\right]$} \\
\hline $136 \mathrm{Xe}+{ }^{208} \mathrm{~Pb}$ & 4428 & 1.5 & $\vartheta$ & 448 & 1120 & 1.5 & 243.1 & 418.0 & 390 & {$[87]$} \\
\hline${ }^{136} \mathrm{Xe}+{ }^{209} \mathrm{Bi}$ & 4482 & 1.5 & $v$ & 454 & 1130 & 1.5 & 244.8 & 421.5 & 393 & {$\left[\begin{array}{ll}88 & ]\end{array}\right.$} \\
\hline
\end{tabular}

Table I : $Z_{\mathrm{p}} z_{\mathrm{T}}$ atomic number product for target and projectile

$M_{H} / M_{L}$ mass asymmetry in the entrance channel

$\mathrm{B}^{\mathrm{H}}$ : Barrier computed in the energy density formalism [12]

When the potential energy curve versus separation distance does not exhibit any barrier ( $\mathrm{zpzt}>2800$ the value of the remaining plateau is estimated

$n$ : Sommerfeld parameter $\underline{z z t \sqrt{\mu}} \eta^{\prime}$ : Sommerfeld 1ike parameter $\underline{\underline{\mu} z t \sqrt{\mu}}$

$$
\pi \sqrt{2 \mathrm{E}}
$$

1 is the angular momentum for the two nucleides at a closest distance of approach corresponding to the barrier top. For ZpZt > 2800, where there is no longer a barrier the distance has been estimated by extrapolating the computed distances for lower zpzt products. The calculated 1 valuesdo not correspond to 1 max since the nuclear potential at this distance is about $40 \mathrm{MeV}$. They are shown to give some hint of the 1 waves involved in the different systems.

The "relaxed" energy.

It was shown, in the yield contour plots for the different elements, that their mean kinetic energy after decreasing with decreasing $\theta$ was reaching a lower limit. Very early Volkov [78, 80] pointed out that this energy was in good agreement with the kinetic energy one would expect from a pure Coulomb repulsion between two correlated fragments A nice proof of the Coulomb origin of the kinetic energy was given at Berkeley [89]. The relaxed kinetic energy of a given element issued from either $\left(18^{\mathrm{Ar}+}{ }_{4} \mathrm{Ag}\right)$ or $\left(36^{\mathrm{Kr}+}{ }_{29} \mathrm{Cu}\right)$ system was found to be the same in both systems. This is expected from a Coulomb repulsion since the total charge is the same for both systems. For very asymmetric splits in light systems there is generally a fairly good agreement between the measured energy and the Coulomb energy repulsion of two spherical nuclei.
However, when approaching mass symmetry in the exit channel, the experimental value is generally lower than the computed one as shown in figure 9 [73]. This is even more clearly stressed in systems involving heavier nucleides where the projectile-like kinetic energy is much lower than the interaction barrier energy. Thus, the ratio between the interaction barrier and the kinetic energy in the exit channel drops from $1 . \pm_{0} .05$ for $(\mathrm{Ar}+\mathrm{Ne})$ to $0.76 \pm 0.08$ for $(A r+A g)$ or to $0.81 \pm 0.10$ for $(A r+A u)$.

An explanation of this difference may be found in the fragment deformation at the scission point. Coulomb energies computed in considering the fragments as spheroids, allowed to attain their equilibrium deformation, are in better agreement with experiment.

However, such calculations are not expected to reproduce more than the gross pattern 
since two effects are not accounted for. A first correction should be introduced in the experimental energy values to account for the particles emitted by the in-flight product. However, this correction is difficult to estimate since, most of the time, very little is experimentally known about the excitation energy left into the fragments. Moreover depending on the nature of the product, the spin and excitation energy, proton and a-particles may be strongly competing with neutrons. This would require more sophisticated corrections than the ones generally introduced assuming only neutron evaporation.

The second correction is related to angular momentum. In the computed kinetic energy in addition to the dominant Coulomb term, one must consider the centrifugal term. As it will be shown in the next section, due to the tangential friction involved in the process, a part of the entrance channel orbital angular momentum is found as intrinsic angular momentum in the reaction products. Therefore, the amount of the remaining centrifugal energy depends on the strength of the tangential force and so far very little is experimentally known in this respect. In the framework of the sticking model one can get an estimate about the importance of the centrifugal term. Let's consider as an example the $(\mathrm{Ne}+\mathrm{Ag})$ reaction with $l_{i}=75 \hbar$. When the two nucleides just come in contact the centrifugal energy is equal to $58 \mathrm{MeV}$. Then, assuming a sticking condition without any mass transfer, the remaining orbital angular momentum $\ell_{f}$ is given by :

$$
\ell_{f}=\frac{\mu\left(R_{1}+R_{2}\right)^{2} \ell_{i}}{\mu\left(R_{1}+R_{2}\right)^{2}+2 / 5 M_{1} R_{2}+2 / 5 M_{2} R_{2}^{2}}=0.58 l_{i}
$$

This gives a centrifugal contribution to the kinetic energy $\mathrm{E}_{\mathrm{C}} \simeq 20 \mathrm{MeV}$. This value has to be compared with the 60-70 MeV of total Coulomb energy and is shown to be quite important. We can notice that, assuming the two nuclei rolling on each other, instead of sticking, the centrifugal term would be even larger ( $(30 \mathrm{MeV})$. This amounts for nearly $50 \%$ of the Coulomb term.

To better understand the importance of the different terms contributing to the measured kinetic energy several experiments were done on a given system with different bombarding energies [83, 62]. As shown also in figure 7 [73] the bombarding energy does not influence in an appreciable way the kinetic energies in the exit channel. However, as it has been observed in several cases [90], with the increase of bombarding energy one would expect an increase of the partial average $\ell$ wave values contributing to deep inelastic reactions and thus an increase of the centrifugal term. But, on the other hand, more excitation energy is left into the fragments leading to larger losses of nucleons and maybe a larger stretching is taking place. These three effects seem to counteract each other. A similar behavior has been pointed out in heavy ion induced fission $[91-92]$.

As far as spectra far from the grazing angle are considered, the energy spectrum FWHM seems not to be $Z$ dependant for most of the studied systems. An increase in FWHM can be observed with increasing bombarding energy [70]. And as for the mean kinetic energy, it is difficult to account precisely for the FWHM since shape fluctuations, angular momentum distributions, excitation energy and particle evaporation all contribute to the observed width.

\section{EXCITATION ENERGY AND SPIN IN THE REACTION PRODUCTS .}

As shown previously, a large amount of the kinetic energy in the relative motion is lost in deep inelastic processes. In order to better understand the reaction mechanism, the knowledge of both excitation energy (heat and deformation energy) and spin for either correlated reaction product would be a valuable information. From the spin values one could estimate the importance of tangential friction in the energy damping.

Experimentally the measurements of both quantities (excitation energy and spin) is a difficult task. Excitation energies can be reached through the measurements of light particles and $\gamma$ rays emitted by the products. Spins can be estimated from the number of $\gamma$-rays emitted during the reaction if evaporated particles are assumed to not carry away much angular momentum.

Coincidence experiments between the fragments and its evaporated particles and $\gamma$-rays are thus required and this generally implies very low counting rates. Most of these experiments are in their early stage and the conclusion we can draw out are rather uncertain.

A- Emission of light particles in deep inelastic reactions.

In the first stage of the interaction 

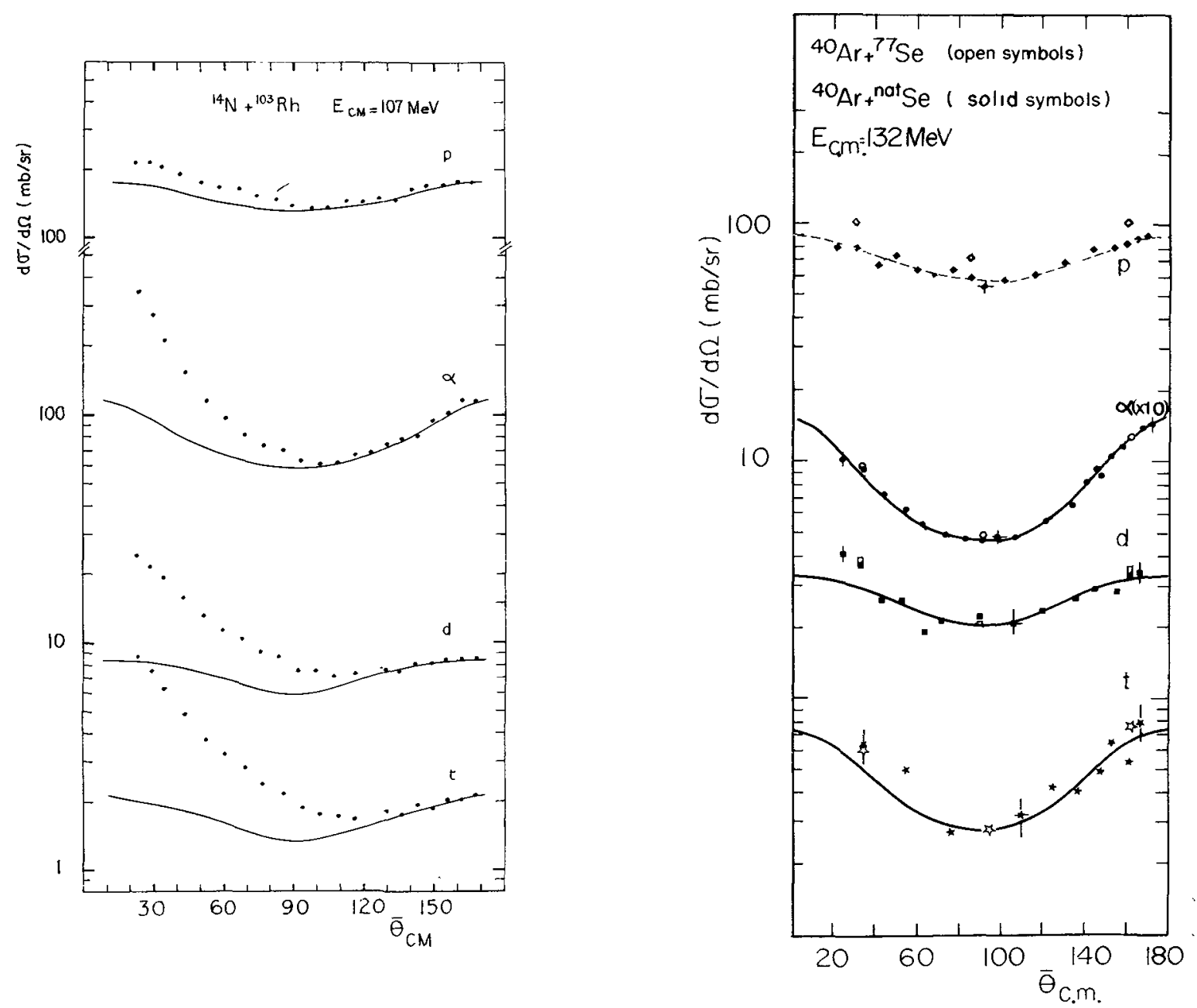

Fig. 10 - Angular distribution of the light charged particles emitted in the reaction ${ }^{14} \mathrm{~N}+103 \mathrm{Rh}$ and $40 \mathrm{Ar}+{ }^{77} \mathrm{Se}$ at bombarding energies adjusted in order to reach the same excitation energy in the II7Te compound nucleus. The solid lines indicate the expected contribution from compound nucleus deexcitation. For details see ref. [90].

process most of the heat might be concentrated in the neck which has developed between the colliding nuclei. It is likely that one or several particles will be emitted from the corresponding hot spot. Such particles are expected to have rather high energies as in preequilibrium emission. Then, provided the life time of the system is long enough, the remaining heat is likely to diffuse throughout the composite system until a uniform temperature is reached. If it were so, the excitation energies left in the two correlated nuclei would be roughly in the ratio of their masses [93-94].

Are there any experimental evidence to sustain the previous assumptions ? i.e. :

- high energy particles emitted prior to scission.
- post scission emission.

In the experimental results we can distinguish four types of measurements :

$\left.1^{\circ}\right)$ Detection of charged particles $(p, \alpha)$ in heavy ion interactions without coincidence requirements with correlated fragments.

It was shown very early $[95]$ that the angular distribution of charged particles emitted in heavy ion interactions was not always symmetric around $90^{\circ}$ as expected from compound nucleus der excitation. Instead, a foreward peaking distribution, in excess as compared with the backward distribution, strongly substantiates the existence of additional reaction mechanisms. Non-compound $\alpha-$ particles are generally more abundant than noncompound protons and deuterons in ${ }^{12} \mathrm{C},{ }^{14} \mathrm{~N},{ }^{16} \mathrm{O}$ 
induced reactions. The $\alpha$-particle kinetic energy may indicate they are issued from a break up of the projectile in the field of the target nucleus. The peculiar abundance of these $\alpha$-particles in ${ }^{12} \mathrm{C}$ and ${ }^{16} \mathrm{O}$ as compared to ${ }^{14} \mathrm{~N}$ induced reactions corroborates the break up explanation.

However more recent experiments have raised puzzling questions [90]. In the study of two systems involving the same global number of nucleons through two quite difference entrance channels $\left({ }^{14} \mathrm{~N}\right.$ $+{ }^{103} \mathrm{Rh}$ and $40 \mathrm{Ar}+{ }^{77} \mathrm{Se}$ ) the emission of light particles from a non compound mechanism was found negligible in the Ar induced reaction as compared with the $\mathbb{N}$ induced one as shown in figure 10. The reason of this difference is not well understood as yet. Furthermore the direct proton mean energy was too high for a break up of the $N$ projectile to be a satisfactory explanation. Similarly the direct $\alpha-$ particle energy spectra extend toward too high energies for all these o-particles to originate from a projectile break up as seen figure 11. However,

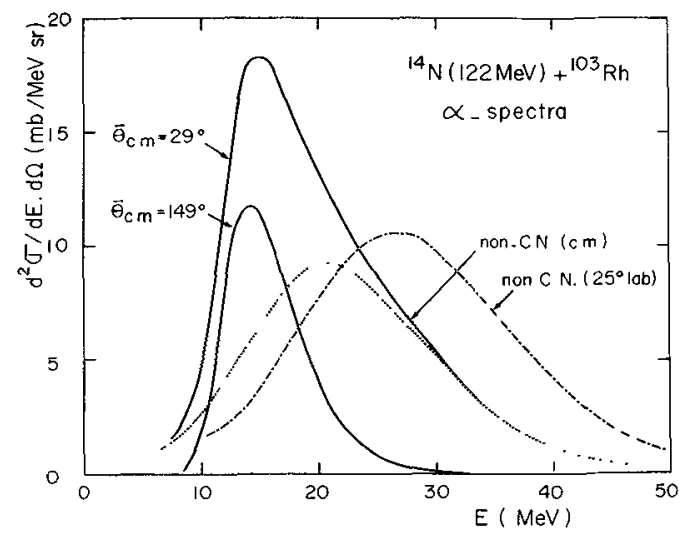

Fig. 11 - In solid lines are given the measured $\alpha$-particle energy spectra at two average c.m. angles symmetric with respect to $90^{\circ}$. (The non-compound contribution (dashed line) is carried out by difference).

without a coincidence experiment in which a fragment is well identified and localized it seems quite difficult to carry out valuable informations about the particles emitted prior or after scission. Indeed too many channels are open and, furthermore, as opposed to the compound nucleus case, the angular distribution of the nucleus which evaporates 1ight particles is quite complex.

$\left.2^{\circ}\right)$ Coincidence experiments between deep inelastic products and light particles.

When a light particle is emitted in coincidence with a massive product, this does not directly indicate at what stage of the reaction or by which fragment the particle has been emitted. One must rely on the recoil energy of the mother nucleus to know which one has emitted the light particle. In particular the case of very asymmetric splits is interesting because the velocity of the light fragment is much larger than that of the heavy one. Simple Monte Carlo simulations [96-97] show in a such case a narrow distribution of emitted light particules by the light fragment around its emission angle, whereas the particles emitted by the correlated heavy fragment are not scestrongly focused in the laboratory frame. It is probably more difficult to get any a priori idea about the pre-scission emission.

Some preliminary results are given in different contribution to this conference [98-101]. In both $\left({ }^{14} \mathrm{~N}+{ }^{93} \mathrm{Nb}\right)$ [99] and $\left({ }^{16} \mathrm{O}+{ }^{58} \mathrm{Ni}\right)$ [98] systems $p$ and $\alpha$-particles have been measured in coincidence with deep inelastic products detected in a fixed direction. The $p$ and $\alpha$-particles angular distributions are well peaked but the maxima coincide with neither light nor heavy product emission angles. As already observed without coincidence measurements the maxima are rather located very near the beam direction. This could indicate that most of the light particles are emitted prior to scission. Furthermore in the second system the $p$ and $\alpha$ particles are strongly focused in the reaction plane signifying an emission from aligned systems having large angular momenta as expected from a strong tangentiel friction.

In addition to the near $0^{\circ}$ contribution there is a smaller and flat contribution which has also been observed in the $\left({ }^{40} \mathrm{Ar}+{ }^{58} \mathrm{Ni}\right)$ system [101] and which could be attributed to the heavy fragment emission. Much more information is needed to get a better insight into the light particle emission process through this kind of coincidence experiments.

$3^{\circ}$ ) Coincidence experiments between the fragments.

The emission of light particles by the fragments results in a broadening of their angular distribution. The out of plane angular width can be used to estimate the number of emitted nucleons, making some assumptions on their nature, spatial distribution and energy. In a system like ${ }^{32} \mathrm{~S}+{ }^{50} \mathrm{Ti}[71]$ it was shown that 3 nucleons were evaporated by both fragments and that an $\alpha$-particle 
emission was quite unlikely. However, in this experiment, it was not possible to decide whether the particles were arising from the pre-scission or post-scission stage. In another type of experiment [102] one can obtain the average "pre-evaporation" mass of the fragments by measuring both correlated fragment velocities (it is assumed that the evaporation does not modify the velocities). On the other hand the "post-evaporation" mass can be obtained by measuring the kinetic energy in addition to the velocity. Evaporation has been found to increase almost linearly with the mass of the light products. This seems consistent with a sharing of the total excitation energy between the two fragments according to their masses.

$\left.4^{\circ}\right)$ Special case of a symmetric entrance channel.

In the Ca-Ca system [103] the yield versus atomic number and mass of the products has
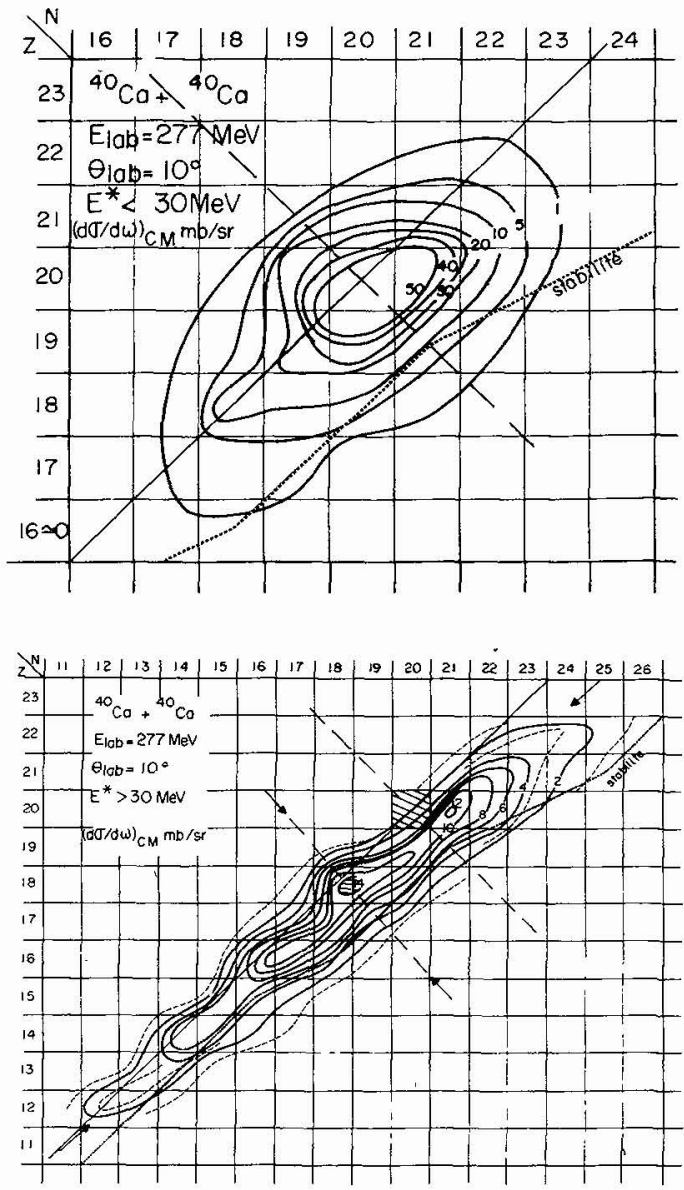

Fig. 12 - Mass and charge yields in the reaction ${ }^{40} \mathrm{Ca}+{ }^{40} \mathrm{Ca}$ for both quasi elastic and strongly damped collisions [72]. been observed to be peaked around $\mathrm{Z} \simeq 18 \mathrm{M}$ 36 showing clearly the average emission of 2 protons and 2 neutrons per product in a symmetric split for strongly damped collisions. However this does not indicate at what stage of the process these particles have been emitted (fig. 12).

B- $\gamma$-multiplicity in deep inelastic reactions. After having considered the damping of the relative motion as due to the action of friction forces, one can get a better insight into the process by studying the effect of friction on the initial orbital angular momentum. The tangential component of the friction force acts by means of a sliding term making the two bodies roll on each other and by means of a rolling friction term causing the two bodies to get stuck rigidly [18-26]. Depending on the strenght of the tangential friction force, a more or less important part of the initial relative orbital angular momentum is transfered into intrinsic angular momentum of the fragments.

In most of the existing dynamic models $[9-10]$ the frictional force (its range, the relative importance of radial versus tangential friction) has been adjusted to account mainly for the kinetic energy loss since data concerning the angular momentum transfer were not available.

When the reaction products are not very excited it is assumed that most of their intrinsic angular momentum is carried of through $\gamma_{-}$ rays and very little by particle emission. Therefore experiments similar to the ones conducted in compound nucleus studies have been undertaken to measure the $\gamma$-multiplicity. A reaction channel is selected by a heavy particle detector and the $\gamma-$ multiplicity for this particular channel is given by means of one or several NaI detectors in coincidence with the particle detector according to the relationship :

$$
\mathrm{N} \gamma=\frac{\mathrm{I}_{\text {coinc }}}{\mathrm{I}_{\text {sing }}{ }^{\varepsilon}}
$$

where $I_{\text {coinc }}$ is the number of coincidences, $I_{\text {sing }}$ the total number of counts on the particle detector for the selected channel, and $\varepsilon$ the $\gamma$-detector efficiency.

An example of $\gamma$-multiplicity determination is given in figures $13-14$. The $\gamma$-ray spa- 


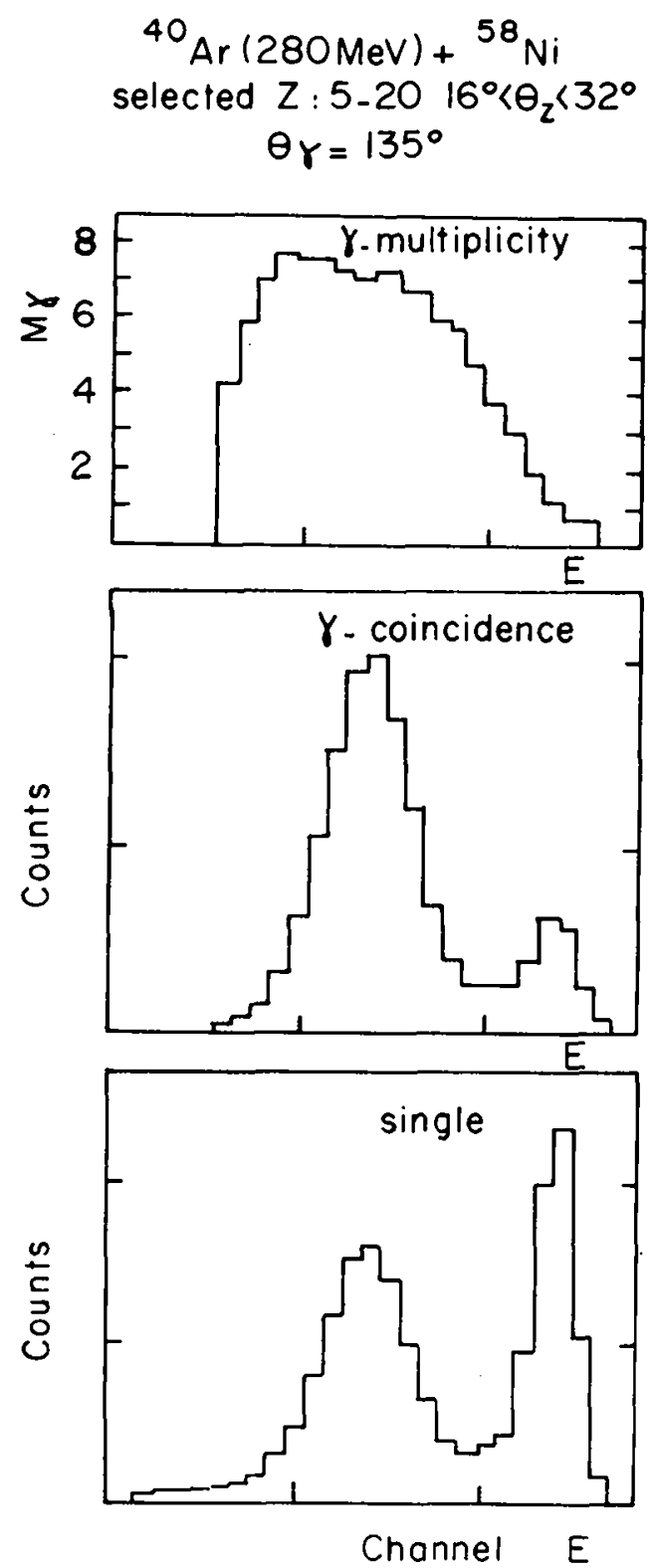

Fig. 13 - Bottom : Single energy spectrum for $5<\mathrm{Z}<20$ at $16^{\circ}<\theta 1 a b^{<}<32^{\circ}$ in the reaction ${ }_{10}^{\circ} \mathrm{Ar}(280 \mathrm{MeV})+58 \mathrm{Ni}[101]$.

Middle : $\gamma$-coincidence spectrum in the same conditions as previously with $\gamma$-rays detected in the reaction plane at $-135^{\circ}$.

Top : Deduced $\gamma$-multiplicity versus kinetic energy.

tial distribution is generally taken into account by averaging the measurements on several $\gamma$-counters located at different angles. Two assumptions have further to be made in order to carry out the spin values from the measured $\gamma$-multiplicity. The first hypothesis is relative to the number of $\mathrm{h}$ units removed per $\gamma$-transition. In the deep inelastic studies the authors have generally relied on data obtained

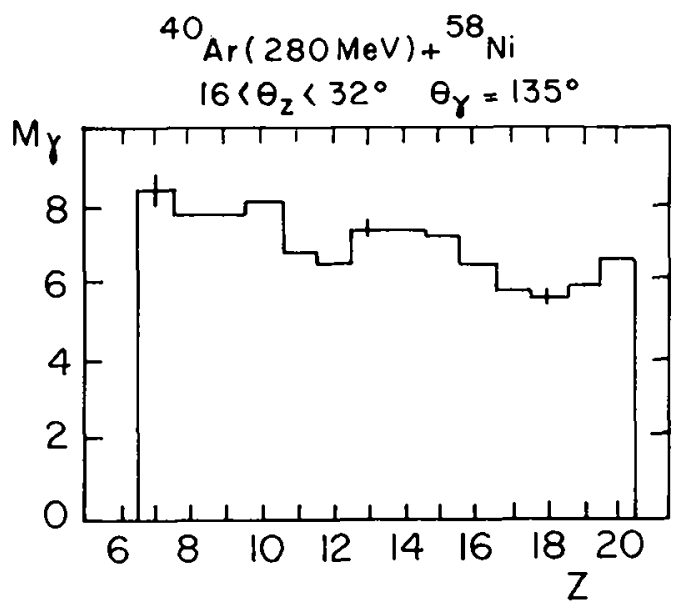

Fig. $14-\gamma$-multiplicity for the different elements produced at $16^{\circ}<\theta 1 a b^{<}<32^{\circ}$ with a kinetic energy below $190 \mathrm{MeV}$ (deep inelastic collisions $)$ in the ${ }^{40} \mathrm{Ar}(280 \mathrm{MeV})+{ }^{58} \mathrm{Ni}$ system $[101]$.

in compound nucleus studies for similax systems. Also, it has been shown,by Grover, Gilat [106] and by Banaschik et al [107] more recently, that $\gamma_{\text {- }}$ rays arising from the YRAST cascade are mainly stretched $E_{2}$ whereas in the statistical cascade stretched $E_{1}$ are the most abundant transitions. A value close to 2 has generally been used $[104,105,108]$. The second ambiguity lies in the angular momentum carried of by particle emission prior to the $\gamma$-cascade. If neutrons or protons can only remove very little angular momentum, for $\alpha$-particle emission the removed angular momentum is certainly not negligeable but is quite difficult to be estimated.

The experimental spin values obtained for the $\mathrm{N}+\mathrm{Nb}$ system [105] are in good agreement with the sticking hypothesis. Within the framework of this hypothesis the orbital angular momentum in the exit channel $\left(l_{f}\right)$ is found to be the following fraction of the initial one $\left(l_{i}\right)$ :

$$
\frac{\ell_{f}}{\ell_{i}}=\frac{\mu\left(R_{1}+R_{2}\right)^{2}}{\mu\left(R_{1}+R_{2}\right)^{2}+\frac{2}{5} M_{1} R_{1}+\frac{2}{5} M_{2} R_{2}^{2}}
$$

where $\mu$ is the reduced mass of the system schematized by two tangent spherical nuclei of mass $M_{1}, M_{2}$ and radius $R_{1}, R_{2}$. Then, the ratio of the two fragment spins is given by the ratio of their moment of inertia :

$$
\frac{\ell_{1}}{\ell_{2}}=\frac{M_{1} r_{1}^{2}}{M_{2} r_{2}^{2}}={\frac{M_{1}}{M_{2}}}^{5 / 3}
$$


This leads to a quite negligeable spin value for the light fragment in asymmetric splits.

For the $(\mathrm{Ar}+\mathrm{Ni})$ system $[101]$ (fig. 13) the $\gamma$ multiplicity is found to be slightly increasing with the products mass asymetry. This is expected from the sticking condition. However, even assuming all $\gamma$-rays as $E_{2}$ the total measured spin is 40 to $60 \%$ less than the one expected from the sticking model. It is rather difficult to know whether this difference can be explained only by the angular momentum carried away by $\alpha$-particles.

It must be noticed that in all these studies the global multiplicity for both fragments is determined.Some attempts have been made recently to study the continuum $\gamma$-spectra in order to try to distinguish the contributions from either fragments for an asymetric entrance channe1.

For a much heavier system such as $(\mathrm{Cu}+\mathrm{Au})[108]$ a $\gamma$-multiplicity approximately half the one expected in the sticking hypothesis was found. However, it is difficult to draw any conclusion from this example since many reasons can be found to account for the difference. First, the angular momentum carried away by $\alpha$-particles is neglected, then, as suggested by a recent work [48], gold like products might be left in isomeric states. Furthermore, for such an heavy system the nearly complete range of $\ell$ waves is involved in the deep inelastic process, contrarily to light systems where a narrower $\ell$ window is involved (and therefore $\langle\ell>$ in the entrance channel is better known). Finally, so far undeformed spherical nuclei are considered in the sticking model although, as shown in section 3 , stretched configurations should be considered.

Another striking result, common to the different experiments $[101,104,108]$ has been found by measuring $\gamma$-ray multiplicity in and out the reaction plane. The distribution is nearly isotropic as though the expected alignment, suggested by the $\alpha$-particle in-plan focusing, was destroyed.

To conclude this section it seems that coincidence measurements between the correlated products, and between one product and $\gamma$-rays or light particles are quite complementary and needed to be done simultaneously on a given system if one wants to better understand what appears to be at the present time as a rather very complicated reaction mechanism.

\section{RELAXATION OF THE NEUTRON EXCESS COLLECTIVE} DEGREE OF FREEDOM

In a system where projectile and target are characterized by different neutron over proton ratios it is interesting to know how is shared the neutron excess in the reaction products. The corresponding degree of freedom is very rapidly relaxed as it can be seen from the experimental evidences described thereafter. These studies require both charge and mass identifications and, so far, mostly light systems (or at least systems involving a light or medium projectile) have been investigated with the masses well resolved up to Mn60 and atomic numbers up to $z=30-35$.

In a first experiment $[58],{ }^{40} \mathrm{Ca}$ and ${ }^{40} \mathrm{Ar}$ projectiles were chosen to bombard both neutron poor ${ }^{58} \mathrm{Ni}$ and neutron rich ${ }^{64} \mathrm{Ni}$ isotopes in order to combine in all the different ways relatively neutron rich and neutron poor targets and projectiles.

A typical isotope yield distribution is given in figure 15 for the ${ }^{40} \mathrm{Ar}+{ }^{58} \mathrm{Ni}$ entrance channel. Near the grazing angle where quasi elastic and completely damped phenomena are well uistinguished it can be seen how different are the mass distributions for the two reaction mechanisms. In a grazing collision the most probable $\mathrm{cl}$ isotope to be formed is ${ }^{39} \mathrm{Cl}$ resulting from a single proton stripping. Nevertheless in these distant collisions

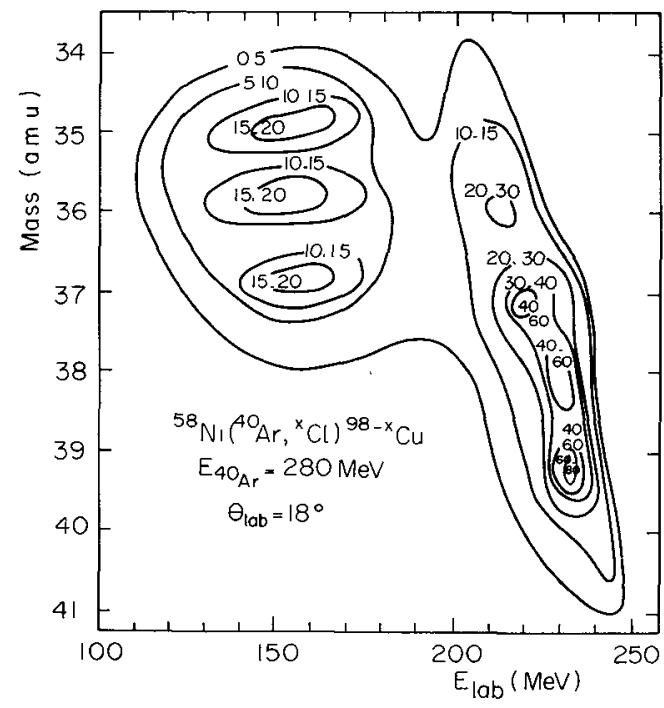

Fig. 15 - Contour plot of the $\mathrm{Cl}$ isotope yields (a.u.) in the $M, E$ plane in the reaction ${ }^{40} \mathrm{Ar}(280 \mathrm{MeV})+58 \mathrm{Ni}$ [unpublished data from orsay]. 
Cl isotopes ranging from ${ }^{34} \mathrm{Cl}$ up to ${ }^{41} \mathrm{Cl}$ have also been found with sizeable cross sections. There is some evidence for the lightest ones to be formed with a slightly lower average kinetic energy than $38-39-40 \mathrm{Cl}$ indicating some energy relaxation in the relative motion and hence corresponding to slightly deeper collisions than the ones leading to $38-39-40$ C1. On the other hand, in the fully energy damped component the heaviest $\mathrm{Cl}$ isotopes are completely missing. Such a trend is qualitatively understandable in terms of a neutron excess degree of freedom relaxation : in the entrance channel the target can be considered as neutron poor as compared to the projectile and will gain in the deep inelastic inte-
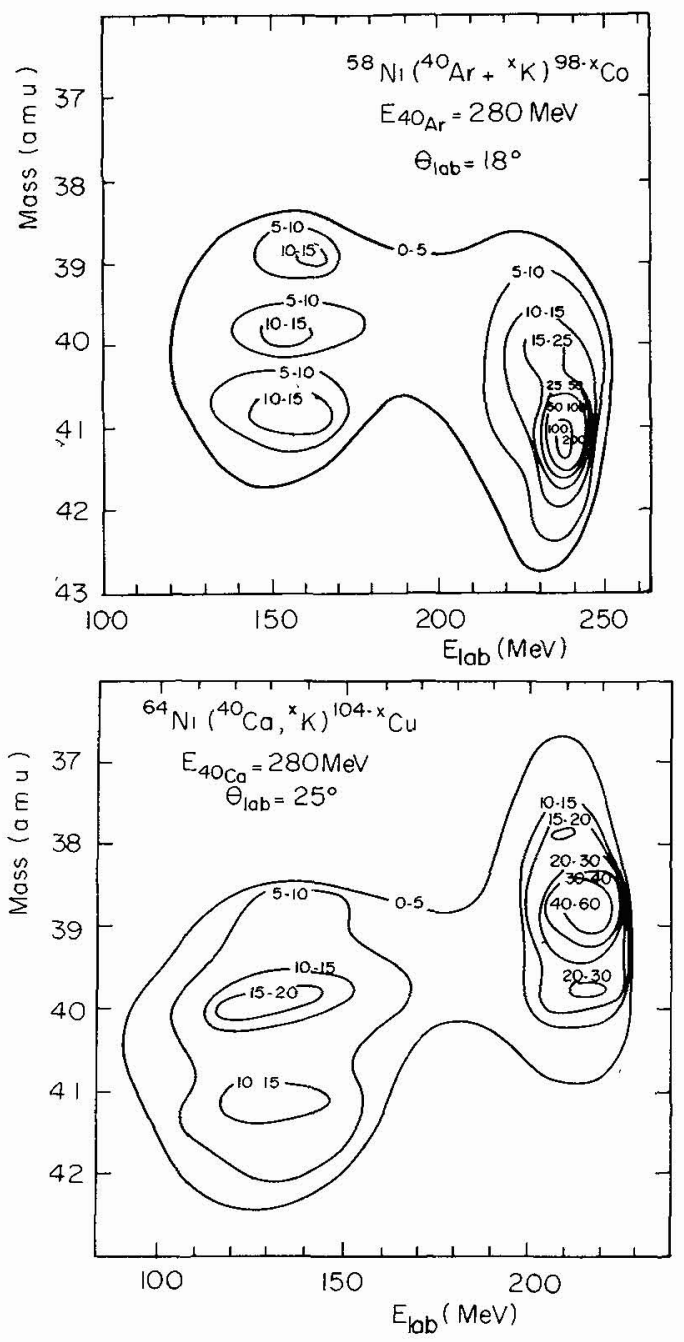

Fig. 16 - Contour plot of the $\mathrm{K}$ isotope yields (a.u.) in the $M, E$ plane in the reactions ${ }^{40} \mathrm{Ar}(280 \mathrm{MeV})+58 \mathrm{Ni}$ and ${ }^{40} \mathrm{Ca}$ $(280 \mathrm{MeV})+6{ }^{4} \mathrm{Ni}[44]$. raction some neutrons at the expense of the projectile.

The same behavior can also be observed qualitatively in the comparison of $\mathrm{K}$ isotopic distributions issued from the two $\left({ }^{40} \mathrm{Ca}+{ }^{64} \mathrm{Ni}\right)$ and $\left({ }^{40} \mathrm{Ar}+{ }^{58} \mathrm{Ni}\right.$ ) systems (fig. 16). These two systems are very similar in their global $\mathrm{N} / \mathrm{Z}$ ratios, although in the first case the projectile can be considered as neutron poor as compared to the target and the reverse is true in the second case. In the energy relaxed components, the mass distributions are very similar to each other as one would expect from a strong rearrangement in the neutron versus proton distribution.

Some quantitative estimates based on potential energy considerations, as suggested by Moretto, have been done for checking whether the neutron excess mode could be considered as fully relaxed. Considering a composite system, assumed for the sake of simplicity to be made of two tangent spherical nuclei, one can compute, for each mass asymmetry the potential energy of the system as a function of the $Z$ distribution. The most probable $Z$ product is expected to be the one which minimizes the potential energy written as follows :

$$
V=E_{1 L D}+E_{2 L D}+V_{c}
$$

where $\mathrm{E}_{\mathrm{LD}}$ is the liquid drop energy for each nucleus in the composite system and $v_{c}$ the conventional coulomb energy.

The results of such an approach are shown in figure 17 and compared to the experimental data. At first glance the agreement appears to be quite satisfactory at least in three out of the four systems. The gross pattern is well reproduced since both calculated and experimental distributions exhibit on average the same neutron excess increase with mass of the light fragment. The experimental structure is not observed in the calculations but this is not expected since pairing or shell effects and evaporation corrections are not introduced in the mode1.

The average differences which are observed between experiments and predictions can arise from two origins. First, the shape which has been assigned to the composite system is certainly unrealistic since the fragment kinetic energies clearly indicate a large stretching out at the scission point. Then, so far, we have not considered the 


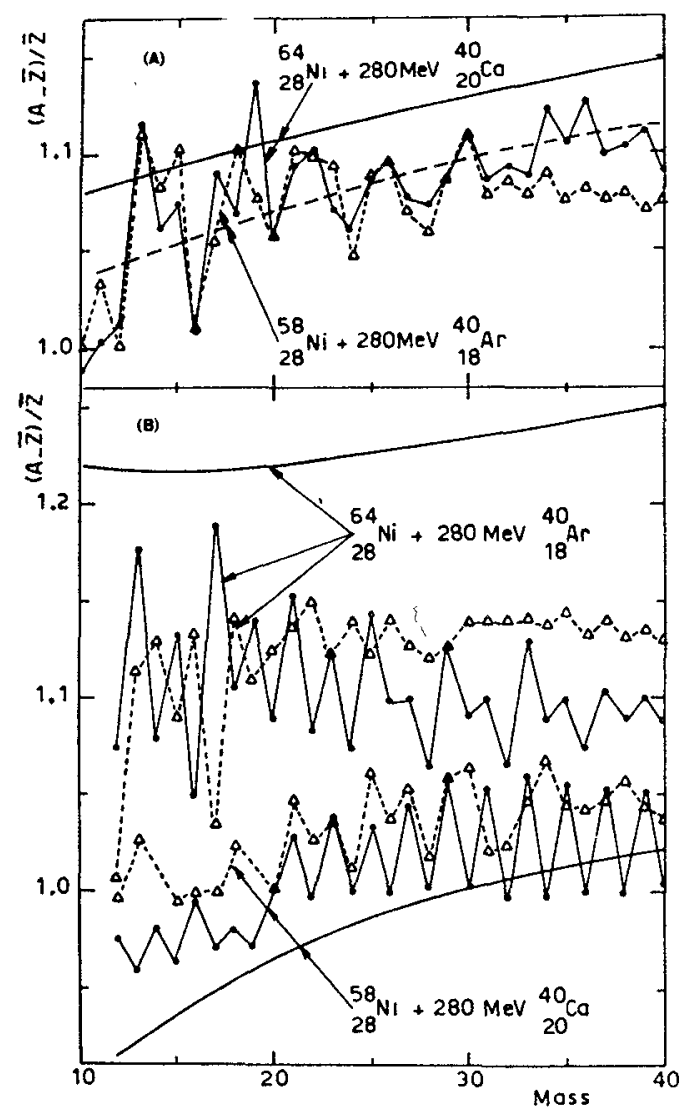

Fig. 17 - (A) The primary distribution calculations (smooth curves) are compared to the experimental measurements.

(B) The primary distribution calculations (smooth curves) and the distribution after the evaporation calculations (dots) are compared to the experimental data (triangles).

large excitation energy left into the fragment which is likely to modify the primary fragment structure because of the particle evaporation.

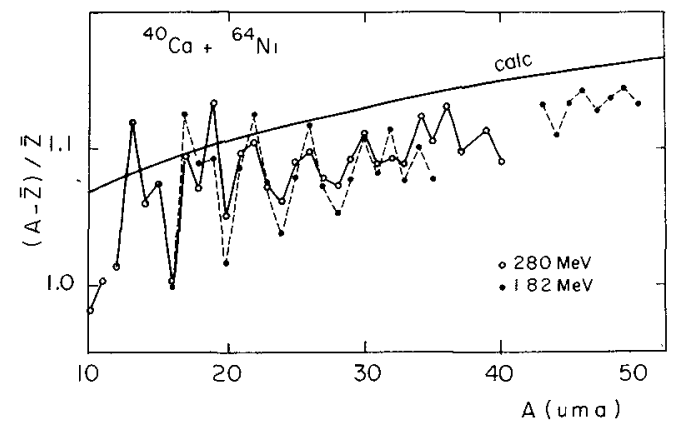

Fig. 18 - Average neutron over proton ratio as a function of product mass for the ${ }^{40} \mathrm{Ca}+{ }^{64} \mathrm{Ni}$ system at $182 \mathrm{MeV}$ and $280 \mathrm{MeV}$ bombarding energy [54].
It is clearly seen that the largest discrepancy between the model and the experimental results was found in the neutron richest system $\left({ }^{40} \mathrm{Ar}+{ }^{64} \mathrm{Ni}\right)$ leading to primary neutron rich nuclei which are supposed to decay mainly by neutron evaporation. Simple evaporation simulations have clearly shown the quantitative importance of the secondary deexcitation phenomena (fig. 17). (Details can be found in ref. 44). We can notice in these simple evaporation calculations how a structured pattern is arising from a primary smooth distribution. Therefore at this point it is quite difficult to ascertain how much the observed structured distribution is already present in the first stage of the reaction before the evaporation process. Modifying the bombarding energy has not allowed to observe fundamental. changes in the $\mathrm{N} / \mathrm{Z}$ distribution ( $\mathrm{fig}$. 18) and the previous question remains open.

Once the charge asymmetry degree of freedom has been shown to be equilibrated for completely damped collisions it is interesting to investigate this mode for intermediate collisions. This is done for a given element by following the isotopic distribution as a function of detection angle. As shown in fig. 19 near the grazing angle the two energy contributions are well separated and isotopic distributions are quite different. Ahead of the grazing angle the completely (or nearly completely) energy relaxed component is still present but is not well separated from the partially damped component. However no significant isotopic distribution difference can be observed as a function of energy. Thus it is clearly shown that the charge asymmetry degree of freedom is equilibrated we11 before the kinetic energy in the relative motion is completely damped.

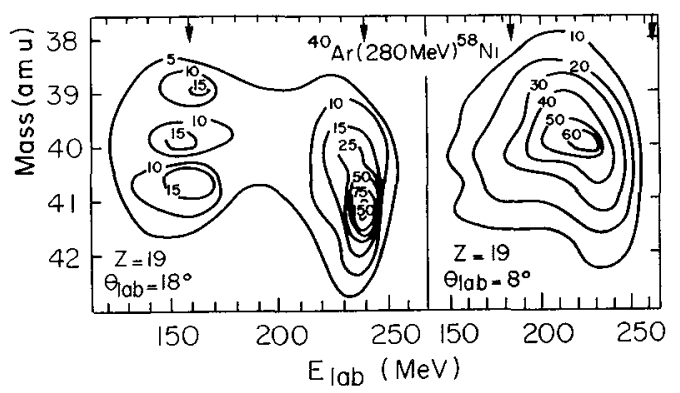

Fig. 19 - Contour plot of $\mathrm{K}$ isotope yields in the $\mathrm{M}, \mathrm{E}$ plane in the reaction $40 \mathrm{Ar}(280 \mathrm{MeV})$ $+{ }^{58} \mathrm{Ni}$ close to the grazing angle (left) and below the grazing angle (right) [53]. 
The kinetic energy being damped in a time significantly smaller than the rotational period we can estimate the characteristic relaxation time for groton over neutron mode to be of the order of $10^{-22} \mathrm{~s}$. The assumption for this mode to be governed by the giant dipole resonance seems to be quite reasonable since for a nucleus of mass 100 the corresponding phonon energy is approximately $\hbar \omega=15 \mathrm{MeV}\left(\tau \sim 2.4 \cdot 10^{-22} \mathrm{~s}\right)$. Finally, in order to confirm experimentally the total relaxation of the charge asymetry mode the following experiment has been realized. The $\left({ }^{40} \mathrm{Ar}+{ }^{64} \mathrm{Zn}\right)$ and $\left({ }^{40} \mathrm{Ca}+{ }^{64} \mathrm{Ni}\right)$ systems in which the same number of protons and neutrons are involved were studied at the same bombarding energy. If the charge over mass mode is the first to be equilibrated, then the two systems must behave exactly in the same way and the products yield after particle deexcitation must be the same as it is clearly shown in figure 20 .

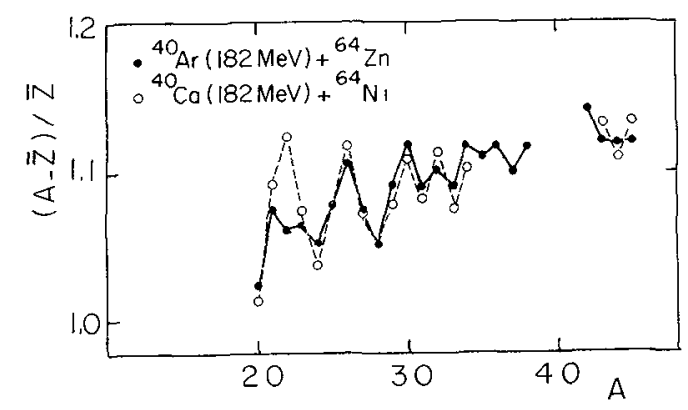

Fig. 20 - Average neutron ovex proton ratio as a Eunction of product mass for the two systems $\left({ }^{40} \mathrm{Ca}+{ }^{64} \mathrm{Ni}\right)$ and $\left({ }^{40} \mathrm{Ar}+{ }^{64} \mathrm{Zn}\right)$ at $182 \mathrm{MeV}$ bombarding energy $[54]$.

Other strong evidence of the neutron over proton equilibration can be found in the study of the system $\mathrm{Ar}+\mathrm{Th}$ [109] and in recent $\mathrm{Cu}$ induced reactions on different targets [110].

SUMMARY AND CONCLUDING REMARKS.

If neglecting the emission of light particles (nucleons or $\alpha$-particles) the twobody character of deep inelastic collisions seems to be well established now.

The size of the interacting nucleides is not the only relevant parameter influencing the reaction mechanism. An increase of the bombarding energy has, to some extend, the same effect as a decrease in the size of the interacting nuclei. A parameter like $z_{1} z_{2} e^{2} / h v^{\prime}$ ( $v^{\prime}$ being the relative velocity at the closest distance of approach), pro- portional to the ratio of a Coulomb conservative force to a dissipative friction force might be a useful parameter in order to classify the studied systems.

The knowledge of both 1ight particle and $\gamma$-ray emission characteristics appears to be very valuable to better understand the friction mechanism. In the present state of the experimental investigation it looks like the usticking hypothesis were verified. As for the sharing of excitation energy between the fragments additional experimental informations are needed to conclude.

The collective neutron over proton ratio mode has been verified as being a very rapidly relaxed one.

\section{ACKNOWLEDGEMENTS}

I would like to thank my colleagues from Berkeley, Darmstadt and Orsay-Saclay for.permission to use in this paper some of their most recent unpublished results.

I am very grateful to $R$. Babinet,

B. Gatty, D. Guerreau, M. Lefort, L.G. Moretto,

H. Nifenecker, C. Ngô, J. Péter, B. Tamain and

$\mathrm{X}$. Tarrago for interesting discussions and critical reading of the manuscript. 
[1] K. Kaufmann and W. Wolfgang, Phys. Rev. 121 (1961) 192

[2] A.G. Artukh, C.V. Avdeichikov, G.F. Gridnev, V.L. Mikheev, V.V. Volkov and J. Wilczynski, Nucl. Phys. A168 (1971) 321 ; Nucl. Phys. A176 (1971) 284

[3] R. Bimbot, H. Gauvin, Y. Le Beyec, M. Lefort, N.T. Porile and B. Tamain, Nucl. Phys. Al89 (1972) 539.

[4] J. Galin, D. Guerreau, M. Lefort, J. Péter and X. Tarrago, Nuc1. Phys. A159 (1970) 1467.

[5] M. Lefort, This conference.

[6] W.J. Swiatecki and S. Bjornholm, Phys. Lett. Reports 4C (19.72) 326 ; W.J. Swiatecki, J. Physique 33 (1972) C5-45.

7 R. Bass, Nucl. Phys. A231 (1974) 45.

8] D.M. Brink and N. Rowley, Nucl. Phys. A2 19 (1974) 79 ; D.M. Brink, This Conference.

[9] D.H.E. Gross and H. Kalinowski, Phys. Lett. 488 (1974) 302 .

[10] J.P. Bondorf, D. Sperber and M.I. Sobel, Phys, Lett. Reports 15C (1974) 83.

[11] J. Randrup, W.J. Swiatecki and C.F. Tsang, Berkeley Preprint (1974) LBL 3603.

[12] J. Galin, D. Guerreau, M. Lefort, X. Tarrago, Phys. Rev. 9 (1974) 1018 - C. Ngô, B. Tamain, J. Galin, M. Beiner and K.J. Lombard, Nucl. Phys. A240 (1973) 353.

[13] J. Wilczynski and K. Siwek-Wilczynska, Phys. Lett. 53B (1975) 270 .

[14] J.R. Nix and A.J. Sierk, Physica Scripta 10A (1974) 401 .

[15] J.P. Blocki, Berkeley Preprint (1975) LBL 4000 166 .

[16] H.J. Krappe, Berlin Preprint (1976).

[17] P. Möller and J.R. Nix, Los Alamos Preprint (1976) 416

[18] C.F. Tsang, Physica Scripta 10A (1974) 90.

19] R.A. Broglia, C.H. Dasso and A. Winther, Phys. Lett. 53B (1974) 301 .

[20] V.M. Strutinski, Phys. Lett. 44B (1973) 245; V.M. Strutinski, This conference.

[21] R.H. Davis, Phys. Rev. 9 (1974) 2411.

22 M.G. Mustafa, Phys. Let $60 \mathrm{~B}$ (1975) 15.

[23] D.H.E. Gross, H. Kalinowski and J.N. De, Lecture Notes in Physics, Heidelberg 33 (1975) 194.

[24] J.P. BondorE, J.R. Huizenga, M.I. Sobel and D. Sperber, Phys. Rev. ClI (1975) 1265.

[25] H.H. Deubler and K. Dietrich, Phys. Lett. 56B (1975) 241 ; H.H. Deubler and K. Dietrich Preprint (1976).

[26] K. Siwek-Wilczynska and J. Wilczynski, Nucl. Phys. A264 (1976) 115.

[27] S.E. Koonin and J.R. Nix, Phys. Rev. C13 (1976) 209 ; S.E. Koonin, Phys. Lett. 6IB $(1 \overline{976}) 227$.

$28]$ P. Bonche, This conference.

[29] L.G. Moretto and J.S. Sventek, Phys. Lett. 58B (1975) 26.; L.G. Moretto, R.P. Babinet, J, Galin and S.G. Thompson, Phys. Lett. 58B (1975) 31.; L.G. Moretto and J.S. Sventek, Berkeley Preprint (1976) LBL 5006.

[30] W. Nörenberg, Phys. Lett. 53B (1974) 289 ; Z. Physik A274 (1975) $24 \mathrm{~J}$.

[31] For details see P. Armbruster, This conference.

[32] K.D. Hildenbrand, H.H. Gutbrod, W. Von Oertzen and R. Bock, Nucl. Phys. Al57 (1970) 297.

[33] M.M. Fowler and R.C. Jared, Nuc1. Instr. and Meth. 124 (1975) 341 .

[34] K. Sistemich, P. Armbruster, J.P. Bocquet, C. Chauvin and Y. Glaize, Nucl. Instr. and Meth. 133 (1976) 163.

[35] L.G. Moretto, B. Cauvin, P. Glässel, R. Jared, P. Russo, J. Sventek and G. Wozniak, Phys. Rev. Lett. 36 (1976) 1069.
[36] J. Moulton, R. Babinet, L.G. Moretto, S.G. Thompson, Berkeley Annual Review (1974) LBL 4000101 .

[37] B. Tamain, C. Ngô, J. Péter, R. Lucas, J. Poitou and $\mathrm{H}$. Nifenecker, Orsay preprint 1975 IPNO-RC75-04 and this conference.

[38] M. Lefort, C. Ngô, J. Péter and B. Tamain, Nucl. Phys. 216A (1973) 166.

[39] K.L. Wolf, J.P. Unik, J.R. Huizenga, J. Birkelund, H. Freiesleben and V.E. Viola, Phys. Rev. Lett. 33 (1974) 1105

[40] G.K. Ge1bke, K.D. Hildenbrand and R. Bock, Nucl. Instr. and Meth. 95 (1971) 397.

[41] T.M. Cormier, R.S. Galik, E.R. Cosman and A.J. Lazzarini, Nucl. Instr. and Meth, 119 (1974) 145 .

[42] A.G. Artukh, V.V. Avdeichikov, J, Ero, G.F. Gridnev, V.L. Mikheev and V.V. Volkov, Nucl. Instr. and Meth. 83 (1970) 72 .

[43] J.C. Jacmart, P. Colombani, H. Doubre, N. N. Frascaria, N. Poffé, M. Riou, J.C. Roynette, C. Stephan, A. Weidinger, Nucl. Phys. A242 (1975) 175 .

[44] B. Gatty, D. Guerreau, M. Lefort, X. Tarrago, J. Galin, B. Cauvin, J. Girard and H. Nifenecker; Nucl. Phys. A253 (1975) 511.

[45] F. Pühlhofer and R. M. Diamond, Nucl. Phys. Al91 (1972) 561 .

[46] J.V. Kratz, A.E. Norris and G.T. Seaborg, Phys. Rev. Lett. 33 (1974) 502 .

[47] R.J. Ot to, M.M. Fowler, D. Lee and G.T. Seaborg Phys. Rev. Lett 36 (1976) 135.

[48] J.V. Kratz, W. Brüchle, I. Dreyer, G. Franz, G. Wirth, M. Schädel, M. Weis, This conference.

[49] U. Reus, A.M. Habbestad-Watzig, R.A. Esterlund and P. Patzelt, This conference.

[50] R. Bimbot, D. Gardès, R.L. Hahn, Y. de Moras and M.F. Rivet, Nucl. Phys. A228 (1974) 85 ; Nucl. Phys. A248 (1975) 377.

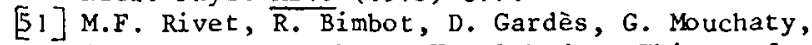
A. Fleury, F. Hubert, Y. Llabador, This conference.

[52] L.G. Moretto, This conference.

[53] J. Galin, B. Gatty, D. Guerreau, M. Lefort, X. Tarrago, R. Babinet, B. Cauvin, J. Girard, H. Nifenecker, Z. Physik, in press.

[54] S. Agarwal, J. Galin, B. Gatty, D. Guerreau, M. Lefort, X. Tarrago, R. Babinet, J. Girard, H. Nifenecker, to be published.

[55] L. Moretto et al., Private communication.

[56] W.J. Swiatecki, Berkeley Preprint (1975) LBL 4296.

[57] J. Wilczynski, Phys. Lett. 47B (1973) 484.

[58] B. Gatty, D. Guerreau, M. Lefort, J. Pouthas, X. Tarrago, J. Galin, B. Cauvin, J. Girard and H. Nifenecker, Z. Physik A273 (1975) 65 .

[59] V.V. Volkov, Proceedings of the Int. Conf. on Reactions Between Complex Nuclei, Nashville (1974).

[60] L.G. Moretto, J. Galin, R. Babinet, Z. Fraenkel, R. Schmitt, R. Jared and S.G. Thompson, Nucl. Phys. A259 (1976) 173.

[61] S. Ouichaoui, C. Ngô, J. Péter, F. Plasil, B. Tamain, M. Berlanger and F. Hanappe, This conference.

[62] B. Tamain, F. Plasil, C. Ngô, J. Péter, $M$. Berlanger and F. Hanappe, Phys. Rev. Lett. 36 (1976) 18, and additional data to be published.

[63] Data from the RAMM group, see K.L. Wolf and C.T. Roche, Proceedings of the macroscopic features of heavy ion collisions, Argonne 1976.

[64] M.P. Webb, R. Vandenbosch and T.D. Thomas, Seattle Preprint 1976. 
65] M. Berlanger, F. Hanappe, C, Ngô, J. Péter F. Plasil and $B$. Tamain, This conference.

[66] E.T. Chulick, M.N. Namboodiri, J.B. Natowitz, Third IAEA Symposium on the Physics and Chemistry of Fission (1973) IAEA-SM-174/104.

67] T.M. Cormier, A.J. Lazzarini, M.A. Neuhausen, A. Sperduto, K. Van Ribber, F, Videbaek, G. Young, E.B. Blum, L. Herreid and W. Thoms, Phys. Rev. C 13 (1976) 682.

[68] J.B. Natowitz, M.N. Namboodiri and E.T. Chulick, Phys. Rev. C 13 (1976) 171.

[69] J. Galin, D. Guerreau, M. Lefort, J. Péter, $\mathrm{X}$. Tarrago and R. Basile, Phys. Rev. 182 (1969) 1267.

[70] L.G. Moretto, S.S. Kataria, R.C. Jared, R. Schmitt and S.G. Thompson, Nucl. Phys. A255 (1975) 491 .

71] P. Braun-Munzinger, G.K. Gelbke, J. Barrette, B. Zeidman, M.J. Levine, A. Gamp, H.L. Harney and Th. Walcher, Phys. Rev. Lett. 36 (1976) 849 .

[72] P. Colombani, N. Frascaria, J.C. Jacmart, M. Riou, C. Stéphan, H. Doubre, N. Poffé, and J.C. Roynette, Phys. Lett. 55B (1975) 45.

[73] R. Babinet, L.G. Morettò, J. Galin, R. Jared, J. Moulton and S.G... Thompson, Nucl. Phys. A258 (1976) 172 .

74] Y. Eyal, K. Beg, D. Logan, J. Miller and A. Zebelman, Phys. Rev. C 8 (1973) 1109.

[75] S. Agarwal, J. Galin, B. Gatty, D. Guerreau, M. Lefort, X. Tarrago, R. Babinet, J. Girard, H. Nifenecker, to be published.

[76] H.C. Britt, B.H. Erkkila, R.H. Stokes, H.H. Gutbrod, F. Plasil, R.L. Ferguson, and M. Blann, Phys. Rev. C 13 (1976) 1483.

[77] J. Galin, L.G. Moretto, R. Babinet, R. Schmitt, R. Jared and S.G. Thompson, Nucl. Phys. A255 (1975) 472

78] A.G.Artukh, G.F. Gridnev, V.L. Mikheev, V.V. Volkov and J. Wilczynski, Nucl. Phys. A211 (1973) 299 and this conference.

[79] C. Ngô, S. Ouichaoui, J. Péter, B. Tamain, M. Berlanger and F. Hanappe, Private communication.

[80] A.G. Artukh, G.F. Gridnev, V.L. Mikheev, V.V. Volkov and J. Wilczynski, Nucl. Phys. A215 (1973) 91 .

[81] R.P. Schmitt, P. Russo, R. Babinet, R. Jared and L.G. Moretto, to be published and see L.G. Moretto, J.S. Sventek, Berkeley: Preprint (1976) LBL 5006.

[82] F. Hanappe, C. Ngô, J. Péter and B. Tamain, Proceedings of the Conf. on Reactions Between Complex Nuclei, Nashville (1974) 116.vol. 1.

[83] J.Péter, C. Ngô and B. Tamain, J. Phys. Lett.

[84] P. Russo, P. Glassel, B. Cauvin, G. Wozniak, R.P. Schmitt, R. Jared and L.G. Moretto, to be published, see L.G. Moretto, J.S. Sventek, Berkeley Preprint (1976), LBL 5006.

[85] F. Hanappe, M. Lefort, C. Ngô, J. Péter and B. Tamain, Phys. Rev. Lett. 32 (1974) 738.

[86] L.G. Moretto et al., Private communication.

[87] R. Vandenbosch, M.P. Webb, T.D. Thomas and M.S. Zisman, Seatt le Preprint (1976).

[88] W.U. Schröder, J.R. Birkelund, J.R. Huizenga, K.L. Wolf, J.P. Unik and V.E. Viola, Phys. Rev. Lett. 36 (1976) 514.

[89] S.G. Thompson, L.G. Moretto, R.C. Jared, R.P. Babinet, J. Galin, M.M. Fowler, R.C. Gatti and J.B. Hunter, Physica Scripta 10A (1974)

[90] J. Galin, B. Gatty, D. Guerreau, C. Rousset, U.C. Schlotthauer-Voss, and X. Tarrago, Phys. Rev. C9 (1974)1113 and 1126 .

[9!] B. Tamain, C. Ngô, J. Péter and F. Hanappe, Nucl. Phys. A252 (1975) 187.
[92] R. Vandenbosch and J.R. Huizenga, "Nuclear Fission", Academic Press, New York (1973).

[93] P.J. Siemens, J.P. Bondorf, D.H.E. Gross and F. Dickmann, Phys . Lett. 36B (1971) 24 .

[94] J.P. Bondorf and W. Nörenberg, Phys. Lett. $44 \mathrm{~B}$ (1973) 487.

[95] H.C. Britt and A.R. Quinton, Phys. Rev. 124 (1961) 877

[96] A. Gobbi, Private commication.

97] D. Benson, G. Catchen, L. Kowalski, D. Logan, N. Lu, J. Miller, U.N. Singh, J. Alexander, T. Debiak and M. Guidry, This conference.

[98] A. Albrecht, C. Bercks, W. Dunnweber, G. Graw, H. Ho, J.P. Wurm, D. Disdier, V. Rauch, F. Scheibling, This conference.

[99] M. Ishihara, H. Kamitsubo, T. Shimoda, F. Fukuda, T. Motobayashi, T. Ohi, I. Kohno, This conference.

100 R. Ost, N.E. Sanderson, J.B.A. England, B. Fulton, G.C. Morrison, This conference.

[101] A. Albrecht, B.B. Back, R. Bock, B. Fisher, A. Gobbi, K. Hildenbrand, W. Kohl, U. Lynen, I. Rode, H. Stelzer, G. Auger, J. Galin and J.M. Lagrange, This conference.

[102] R. Babinet, B. Cauvin, J. Girard, H. Nifenecker, S. Agarwal, J. Galin, B. Gatty, D. Guerreau, $M$. Lefort and $X$. Tarrago, This conference.

103] P. Colombani, N. Frascaria, J.C. Jacmart, M. Riou, C. Stéphan, H. Doubre, N. Poffé, and J.C. Roynette, Phys. Lett. 55B (1975) 45, and this confexence.

104 A. Albrecht, W. Dunnweber, G. Graw, H. Ho, S.G. Steadman, and J.P. Wurm, Phys, Rev. Lett. 34 (1975) 1400 .

[105] M. Ishihara, T. Numao, T. Fukuda, K. Tanaka, $T$. Inamura, Contribution to the Argonne Symposium (1976).

[106] J.R. Grover and J. Gilat, Phys. Rev. 157 (1967) 802 , ibid. 814 .

[107] M.V. Banaschik, R.S. Simon, P. Colombani, D.P. Soroka, F.S. Stephens and R.M. Di amond, Berkeley Preprint (1975) LBL 3456.

[108] M. Berlanger, M.A. Deleplanque, C. Gershel, F. Hanappe, M. Leblanc, J.F. Mayault, C. Ngô, D. Paya, N. Perrin, J. Péter, B. Tamain, L. Valentin, This conference.

[109] J.C. Jacmart, P. Colombani, H. Doubre, N. Frascaria, N. Poffé, M. Riou, J.C. Roynette, C. Stéphan and A. Weidinger, Nucl. Phys. A242 (1975) 175 .

[110] L. Tassangot, N. Frascaria, J.P. Garron, J.C. Jacmart, N. Poffé, C. Stêphan, This Conference. 